Public Journal of Semiotics 7 (1)

\title{
An Assessment of (Mentalist) Cognitive Semantics
}

\author{
Esa Itkonen
}

\begin{abstract}
Common claims within cognitive semantics (e.g. Johnson 1987; Lakoff 1987; Langacker 1987) are that "the most fundamental issue in linguistic theory is the nature of meaning" and "meaning is a matter of conceptualization". But the latter claim creates a problem. On the one hand, for many cognitive semanticists conceptualization takes place under the level of consciousness. On the other hand, semantic analysis is carried out on the level of consciousness, namely by means of (conscious) intuition-cum-introspection. What is, then, meaning? As Wittgenstein argues, meaning is use, understood as a web of intersubjective norms, comparable to rules of a game and accessible to conscious intuition. In this article I elaborate on this claim, and thus offer critique to those who equate linguistic meaning with conceptualizations understood as private mental representations. Furthermore, I argue that the non-causal study of norms (langue) must be kept separate from the causal study of (norm-following or norm-breaking) behaviour (parole). Because of its variationist nature, linguistic behaviour demands statistical explanation.
\end{abstract}

Keywords: conceptualization, meaning-as-image, meaning-as-use, normativity, generalization, statistical causality, intuition, introspection

\section{Introduction}

In the context of North American linguistics the Bloomfield-Harris-Chomsky tradition emphasized (physical) linguistic form at the expense of linguistic meaning (cf. Itkonen, 1996, pp. 483-486, 497-498). The tide turned with the advent of Cognitive Linguistics as indicated in statements such as the following: "We have taken meaning to be the central issue" (Lakoff, 1987, p. 266) and "The most fundamental issue in linguistic theory is the nature of meaning" (Langacker, 1987, p. 5). For many, though not all, cognitive linguists, this meant a psychological (mental) notion of meaning. It is my purpose in this article to scrutinize this meaning-conception.

Section 2 establishes the following analogy: if different conceptualizations of the same "objective situation" are sentence meanings, then the objective situation is like the propositional content $p$ and its conceptualization (minus the objective situation itself) is like the illocutionary force $F$ in the expression $F(p)$. The objective situation, being so named, must be the result of a logically primary conceptualization/verbalization. Section 3 broaches the topic of mental image, duly noting that this term has later been replaced by that of "construal" (cf. Möttönen, 2016). Section 4 introduces the two principal meaning-conceptions, namely "meaning-as-use" and "meaning-as-image", and argues in favour of the former. Section 5 introduces the fundamental distinction between (conscious) intuition and (conscious) introspection: the former applies to what is normative and intersubjective (=meaning-as-use) whereas the latter applies to what is non-normative and subjective (= meaning-as-image). Section 6 reveals a contradiction inherent in (mainstream) cognitive semantics: on the one hand, meaning is identified with conceptualization, which is not accessible to consciousness (or only to a very limited extent); on the other, it is conscious intuition (occasionally combined with introspection) which semantic analysis relies upon.

The second part of the article is more meta-theoretical. In Section 7, the topic of this article is recast in terms of the Popperian ontology of "three worlds": norms/conventions are inhabitants of "world-3" whereas conceptualizations are inhabitants of "world-2". Section 8 disambiguates the key term concept: conceptual relations in the sense of necessary truth or falsity (= analyticity, entailment, contradiction) are sharply distinguished from cognitive processing. In Section 9, the notion of "encyclopedic" meaning is criticized for being too 
inclusive: anything at all that can become an object of "mental experience" is supposed to be handled by cognitive semantics. In Section 10, the two rival meaning-conceptions are compared, based on how they describe first, inference/entailment and second, the meanings of triangle and knowledge. In Section 11, it is shown that an excessive fear of "false dichotomies" brings about a situation where even fully legitimate gradual distinctions have come to be ignored, with disastrous results. Section 12 questions the justification of characterizing one of the main approaches in cognitive linguistics, Cognitive Grammar (Langacker, 1987) as a "usage-based theory", given that it is imaginary, rather than actual, usage that it is based upon. Actual usage exhibits inherent variation, which demands a notion of statistical causality/explanation. The attitude of Cognitive Grammar vis-à-vis such notions as "generalization" and "functional explanation" is discussed in Sections 13 and 14.

Finally, I summarize the main points of the argument in Section 15, and point out that the criticism here formulated applies only to cognitive semantic theories that endorse a mentalist rather than an intersubjective conception of linguistic meaning, as for example Sinha (2007), Harder (2010), Zlatev (2010), Blomberg (2015) and Möttönen (2016).

\section{Objective situation vs conceptualizations}

Within one of the most influential cognitive semantic theories, Cognitive Grammar word and sentence meanings are described by means of many different kinds of diagrams. The example (1) is the first whole sentence described by Langacker (1987) in such a diagrammatic fashion (pp. 94-95). The literal meaning of (1) is described by means of three successive pictures which represent a cat, the out-of-motion, and a bag. In the same vein Lakoff (1987, p. 293) analyzes the meaning of the sentence The cat is on the mat by means of the two mental images of cat and mat (associated with the corresponding concepts) related by the "image schema" for on.

\section{(1) The cat is out of the bag.}

The anti-objectivist aspect of cognitive semantics in both approaches is evident from the constant emphasis on the multiplicity of alternate conceptualizations, as illustrated by Langacker (1987, p. 110-111). The general principle is formulated by Langacker as follows: "Every linguistic expression, at its semantic pole, structures a conceived situation (or scene) by means of a particular [mental] image" (ibid, p. 128). Consider examples (2-5).

(2) The clock is on the table.

(3) The clock is lying on the table.

(4) The clock is resting on the table.

(5) The table is supporting the clock.

Langacker's analysis implies that while (2) may be "the most neutral", all sentences (25) "embody substantially different images (and hence are semantically distinct) even though they could all be used to describe the same objective situation" (emphasis added). The expression in italics is synonymous with "the situation itself", employed by Lakoff \& Johnson (1980, p. 180). Because the "alternate images" are there "for purposes of thought or expression" (ibid, p. 110), they are supposed to precede verbalization.

Let us focus on the objective situation which is common to the conceptualizations expressed by (2-5), i.e. which these are conceptualizations of. It goes without saying that it too must be conceptualized in one way or another, if human beings have no "direct access" to reality (a common assumption both in the Kantian tradition and in cognitive semantics). It is 
indeed a logical necessity that the entity at issue must have been conceptualized, because it has been verbalized by such (synonymous) expressions as "objective situation" or "situation itself" (and verbalization entails conceptualization). But it does not coincide with any of the (more specific) conceptualizations expressed by (2-5), not even with the conceptualization expressed by the "most neutral" sentence (2). Let us designate this (primary) conceptualization by [2-5]. What is it?

Since [2-5] is logically prior to the verbalizations (2-5), it should perhaps be represented by means of a corresponding observable picture, e.g. a photograph. This would display the "substratum" common to (2-5). Incidentally, this is the standard situation in a large variety of psycholinguistic tests where participants are asked to describe pictures they have been shown.

Above, we saw Langacker $(1987$, p. 110, 128) claiming that (2-5) have different meanings because they express different mental images. But this claim entails a vicious circle. It has become evident by now that the mental images expressed by (2-5) are verbalized by definition. They can be distinguished from one another only by means of the corresponding sentences. If you do not believe this, just try to distinguish (3) from (4) on the basis of nothing but the mental images, without any reference to the corresponding sentences. It is impossible. Or, formulated as an understatement: "We overestimate the precision of our imagery" (Koestler, 1967, p. 92).

The definitive status of [2-5] still remains to be determined. Notice that all of (2-5) are in the present tense: they are supposed to express current perceptions. If we change (2-5) into past tense, they express remembered perceptions, and it still makes sense to think that [2-5] represents an "objective situation". But this no longer makes sense if (2-5) are in the future tense: which objective situation could be described both by (3') Will the clock be lying on the table? and by (4') Will the clock be resting on the table? None at all. We have the same result if (2-5) are negated simply because the existence of any objective situation is denied by (3") The clock is not lying on the table. We have the same result if (2-5) are turned into questions. While (2-5) have now undergone several modifications, [2-5] has remained the same insofar as it still represents what is common to (2-5). But it cannot any longer be regarded as the "objective situation". So, to repeat our earlier question: What is it?

Taking his clue from Wittgenstein (1958, §22), Stenius (1960, pp. 162-164) divides each sentence into modal component and sentence-radical, for instance: $I(p)=$ assertion ('you live here now') vs. ?( $p)$ = question ('do you live here now?'); and he then goes on to argue that it is only the sentence-radical which exhibits an "isomorphism" (i.e. diagrammatic iconicity) between language and reality (Itkonen, 1970a, pp. 123-137). Today this dichotomy is better known as "illocutionary force vs. proposition", illustrated by the $F$ vs. $p$ opposition in any expression of the type $F(p)$ (Searle, 1969, pp. 29-33). In the present context, the important thing is to point out the analogy between the so-called objective situation [2-5] and the proposition: both are after-the-fact abstractions from various sentences: these are the primary thing. ${ }^{1}$ On the other hand, this abstraction can be made concrete by means of a picture which needs to be interpreted in one way or another (see Section 5).

The multiplicity of conceptualizations is hardly a novel insight: "Everything in the world is susceptible of multiple categorization" (Brown, 1958, p. 225). Thus, "one and the same thing can be perceived or conceived differently, and may therefore be referred to by different words. Consequently, different ways of perceiving and conceiving must be accepted at the same time as objectively given" (Itkonen, 1970a, p. 102). To be sure, there is no clearcut distinction between conceptualizations which are or are not objectively given: "It may not

${ }^{1}$ While temporally secondary, [2-5], may qualify as logically primary. 
be objectively certain whether e.g. a soldier disobeying orders is a traitor or a hero. On the other hand, it is objectively certain that there is no way of conceiving a soldier as, e.g., a pizza-pie" (ibidem). Kahneman (2011) makes the same point in terms of framing: "some frames are clearly better than alternative ways to describe (or think about) the same thing" (p. 371). In fact, the freedom of conceptualization is so great that the ontological thing vs. action distinction may turn out to be irrelevant for the linguistic reference vs. predication distinction: This soldier is smoking = This smoker is a soldier (Itkonen, 1969b, p. 19-20).

The preceding account has a complicated structure. On the one hand, scholars like Lakoff and Langacker claim that cognitive semantics is "anti-objectivist". At the same time meanings are contrasted with "objective situations" and their "objective properties". But objectivity disappears as soon as we get beyond the simplest sentence-types, i.e. present-tense affirmative assertions about perceived situations.

In other respects as well, the foundations of anti-objectivism do not seem very secure. Lakoff (1987) argues that "there is one psychologically relevant level at which the categories of the mind fit the categories of the world" (p. 34, original emphasis deleted, new emphasis added); and "divisions at the basic level in folk biology correspond to very striking discontinuities in nature ..." (p. 36; emphasis added). What does this mean? Do we, after all, have direct access to the objective "reality itself" (whether we call it "the world" or "nature")? Can we - contra Immanuel Kant - compare the mind and the (mind-independent) reality directly with each other?

Finally, let us note that the description of sentences (1-5) rests on the notion of truth: "Also from the linguistic point of view it is necessary to know what makes a sentence true, assuming that it is true. This attitude is wholly instinctive: in what precedes, for instance, it was taken for granted that sentences [like (1-5)] which express perceptions were imagined to be uttered in situations where the corresponding perceptions indeed occur, i.e. where they were true" (Itkonen, 1969a, pp. 229-230). Knowing the truth condition of an assertion is not the same thing as knowing its meaning, but the former is certainly included in the latter

\section{From mental image to construal}

Initially, the notion of imagery played a central role in Cognitive Grammar: "semantic structure is based on conventional imagery" (Langacker, 1987, p. 111). Among mental images the visual ones have a privileged status, and their affinity with Cognitive Grammar-type diagrams is self-evident. On the other hand, it was clear from the start that these diagrams have a more general function. Besides, the cognition of the blind shows convincingly that the connection with vision is not necessary. It is truly surprising to what extent drawings by blind children resemble those by sighted ones (Kennedy, 1993). If the blind have mental images, these must exploit sensory capacities other than vision. This idea is captured by the more general term sensory image.

It is well-known that the ability to form mental images exhibits interpersonal variation; there are even people who, lacking this ability altogether, exemplify imageless thought (Chafe, 2013, p. 111). The opposite of image-like or pictorial thought is called language-like or digital. According to the majority view today, both types of thinking occur in the normal case (Itkonen, 2005a, pp. 131-136). ${ }^{2}$ In the light of this, there is no justification for assigning a methodologically central role to mental images. It is true, of course, that cognitive semantics

\footnotetext{
${ }^{2}$ Earlier semantic theories relied predominantly on the digital manner of representation. This is what the situation looked like 47 years ago: "It is standard practice today to explicate semantics with the aid of symbolic logic.... Symbolic logic, perhaps in some modified version more adequate to its subject matter, is capable of explicating semantically relevant distinctions not explicated by natural language, and of not explicating semantically irrelevant distinctions explicated by natural language" (Itkonen, 1969a, pp. 227-228).
} 
diagrams of e.g. image schemas (Johnson 1987) represent something, and even something on which it is often easy to agree. But rather than identifying them with mental representations tout court, it may be more prudent to say that they just represent something that we know about language.

As noted above, conventional imagery was claimed to be one of the key concepts of cognitive semantics (Langacker, 1987, p. 111; Lakoff, 1987, p 117). And yet this is a blatant instance of contradictio in adiecto because conventions are social or intersubjective whereas mental images are subjective. ${ }^{3}$ More recently this hybrid notion seems to have been abandoned. For instance, it does not occur in the index of a representative handbook in the field (Geeraerts \& Cuyckens, 2007). Does this mean that the contradiction has been resolved? According to Langacker (2007, p. 424), language is intersubjective because it is an "inventory of conventional units", but units themselves are subjective because they are "patterns of processing activity carried out more or less automatically". Therefore the contradiction remains very much the same as before. ${ }^{4}$

A degree of improvement can be seen in adapting the notion of construal. For instance, sentences (2-5) express different construals of the objective situation [2-5]. It is possible to interpret this notion as corresponding to different conventionalized perspectives (or Frege's Sinn) on the same referential situation, and this give Cognitive Grammar a more intersubjective interpretation (Möttönen, 2016). In fact, the notion of construal has been extended to cover what was earlier referred to by imagery (Langacker, 2007, p. 452, note 22). Still, there is a problem: cognitive semantic diagrams now remain as they were before, although their original image-based motivation has disappeared. This is one way of showing that, contrary to Langacker (2007, p. 421), the essence of Cognitive Grammar has not really remained the same.

\section{Meaning: image or use?}

The essence of the notion of meaning in Cognitive Grammar can be inferred from the following chain of definitions: (a) "meaning is, in the last analysis, a matter of conceptualization" (Langacker, 1987, p. 156). (b) "A conceptualization is the occurrence of a cognitive event" (p. 138). (c) "[C]onceptualization, mental experience, and cognitive processing are proper concerns of semantic analysis" (p. 99) and (d) "[W]e are capable of constructing conceptual worlds $\ldots$ of dreams, ... mathematics, ... and linguistic theories" ( $p$. 113).

These quotations conclusively imply a psychologistic (i.e. mentalist) meaningconception. Itkonen (1991, Ch. 4) documents and discusses those meaning-conceptions that have been current in the history of Western linguistics. This tradition has been dominated by Aristotle's view that linguistic units (i.e. their forms) signify mental units (noēmata, pathēmata). The most important opponents of this psychologistic view include the Stoics (pp. 183-189), Pierre Abaelard (pp. 224-226), Frege and Husserl (within logic) (pp. 284-285) and Wittgenstein (pp. 294-297).

By definition, psychologism concentrates on individual persons. In this respect there is no difference between cognitive semantics and generative linguistics: "Its standpoint is that of

\footnotetext{
${ }^{3}$ In the early 1990's I pointed this out to Langacker in a private discussion, and at least on that particular occasion he agreed.

${ }^{4}$ Some consolation may be derived from the fact that an eminent scholar like de Saussure exemplifies the same contradiction: language is a social institution but the linguistic sign is a psychological entity because it is located in the mind of the individual speaker (cf. Itkonen, 1978, pp. 55-59; 1991, pp. 297-298).
} 
individual psychology" (Chomsky, 1986, p. 3). As for Langacker, this truth is underlined by the fact that he (rather controversially) identifies cognition and neurology: "mental experience resides in cognitive events, defined as neurological occurrences" (1997, p. 249, original emphasis; also 2007, p. 424). The negative definition of antipsychologism is self-evident: meaning cannot be based on mental experience of individual persons. It is less clear what its positive definition is. Frege's answer has aroused much discussion, with recent contributions e.g. by Johnson-Laird (1983, pp. 183-184), Johnson (1987, pp. xxx-xxxi), and Jackendoff (1992, pp. 26-27) (cf. Itkonen 1997, pp. 50-52).

Frege (1949 [1892], pp. 87-88) distinguishes between (extralinguistic) referent, meaning, and mental image. Being a "common property of many", meaning "is not a part or mode of the single person's mind". By contrast, "the [mental] image is subjective; the image of one person is not that of another. Hence, the various differences between the images connected with one and the same meaning". More specifically, "my image [of an object of sense perception] is an inner picture arisen from memories of sense impressions and activities of mine, internal or external, [and f]requently ... suffused with feelings" (emphasis added). (Here "nominatum" has been replaced by "referent", while both "sense" and "connotation", which are defined as synonymous on p. 86, have been replaced by "meaning".) It follows that, when speaking of images, it must always be specified whose images they are (and at which moment they occur). In the same vein, Sapir (1921, pp. 39-41) notes that different "feelingtones" attach to one and the same word. They are not part of the word's meaning, or of its "conceptual core", but vary from one person to another and even from one moment to the next within one and the same person.

Frege's meaning conception has often been assigned a Platonist (and therefore controversial) interpretation. But an expression like "common property of many" seems rather to suggest a social interpretation. How can we make this more explicit?

The most obvious answer is provided by Wittgenstein's slogan: "Meaning is use", or in a more carefully attested form: "Look at the sentence as an instrument, and at its sense as its employment" $(1958, \S 421)$. In order to make his point absolutely clear, he adds a host of specifications:

\begin{abstract}
The meaning of a word is not the experience one has in hearing or saying it, and the sense of a sentence is not a complex of such experiences" (p. 181)

... a meaning of a word is a kind of employment of it. For it is what we learn when the word is incorporated into our language. This is why there exists a correspondence between the concepts 'rule' and 'meaning' (1969, §§61-62).
\end{abstract}

As clarified by Winch (1958, p. 58): “The test of whether a man's actions are the application of a rule is ... whether it makes sense to distinguish between a right and a wrong way of doing things in connection with what he does" (emphasis added). Hence, rule is synonymous with norm, a view sanctioned by von Wright (1963: 6): "The rules of a game are the prototype and standard example of a main type of norm. ... The rules of grammar (morphology and syntax) of a natural language are another example of the same main type of norm as the rules of a game". 5

Wittgenstein further illustrates his "meaning is use" thesis with the aid of several analogies (cf. 1958, §316). Because the checkmate is performed by the last move of a chess

\footnotetext{
${ }^{5}$ Consistent with de Saussure's (1962/1916) remark that, as far as the nature of language is concerned, of all conceivable analogies the most convincing is that "entre le jeu de la langue et une partie d'échecs" (p. 125; also p. 43).
} 
game, one might be misled into thinking that one learns the meaning of checkmate by staring with utmost intensity at the last move of some chess game. But this would be a mistake. The meaning of checkmate cannot be known unless one knows the rules/norms that govern chess games from the beginning to the end. The same is true of meanings in general.

Every instrument has both formal and functional properties. The former are exactly measurable while the latter are not. Yet their existence cannot be denied. The functional properties of a hammer are not those of an axe: nails are driven into (typically) wood with a hammer whereas logs are split with an axe. We see that the functional properties of an instrument are simply identical with its use. As Aristotle already noted, any kind of use is (teleologically) explained on the basis of a means-end relation: an axe has its characteristic form in order to be usable for splitting logs; it is a means for achieving the goal of splitting logs; and achieving this goal serves in turn as a means for achieving higher-level goals ( $D e$ partibus animalium I, 1, 642a: 10-15).

In just the same way the words and sentences of a language are divided into form and meaning/use, and their use constitutes one of the lowest levels in the general hierarchy of actions: "the specific structure of language is determined by its use, i.e. its function of talking about (and influencing) the world, precisely in the same way in which the specific form of e.g. a spade is determined by its function of digging" (Itkonen, 1970a, p. 99.)

In the present context it is vital to understand that the use of instruments (including language) can be, and is, described regardless of what (if anything) goes on within the minds of those individual persons who are using them. For the description to be adequate, it is enough to know the goals which are meant to be achieved by the use of instruments. We use the word $d o g$ to speak about dogs. This is its meaning as well as the goal of its use.

But there is more. "Meaning is use" sounds deceptively simple because it conceals the normative character of instruments. An ignorant person may use - or rather, may try to use an instrument in a wrong way, e.g. to split a $\log$ with the head, and not the blade, of an axe. It is clear that the likelihood of misuse increases with the complexity of instruments. One might be tempted to think that, in order to describe an axe, it is enough to measure it and to videotape an instance of its use. But this is too simple. It needs to be added that the form of an axe ought to be like this and it ought to be used like this. Analogously, the words dog and triangle ought to be used to speak about dogs and triangles, respectively.

Huge amounts of time and energy have been spent on trying to answer the question as to how the meaning of a word or a sentence "exists", i.e. what its ontology is. It does not seem equally difficult to answer the question as to how the use of an axe exists. Still, this question is not quite as simple as it seems. As we just saw, we are not just dealing with its use but with its correct use. Therefore the (correct) use of an axe exists in the same way as, more generally, any norms that govern human behaviour.

On reflection, it is wrong to oppose the use of a linguistic unit and the mental image connected with this unit. As Wittgenstein has argued, every picture/image can be interpreted in many - in fact in infinitely many - ways, and this is true of mental images as well. If we are just shown a picture out of any context, we do not know what to think about it or to do with it: "a picture representing a boxer in a particular stance ... can be used to tell someone how he ... should hold himself; or how he should not hold himself; or how a particular man did stand in such-and-such a place; and so on" (1958, p. 11; emphasis added).

It follows that every picture needs an instruction for its (correct) interpretation or use, even if we are in general unaware of this fundamental fact: "It is not the imagery that gives content to the intellectual thought, but the intellect that gives meaning to the imagery whether imagined words or mental pictures - by using it in a certain way and in a certain context" (Kenny, 1980, p. 78). 
Moreover, the use of a mental image must be public in one way or another. Let us assume that someone is using three different mental images in ten different ways. But if all these uses always remain completely "within" him/her, it is impossible to distinguish them from one another, and nothing can be either known or said about them. Just as well - or better - these (three) mental images and their (ten) uses could be nonexistent: each of them "drops out of consideration as irrelevant" (Wittgenstein, 1958, §293).

From this perspective, mental images exist only as embedded in public - in particular linguistic - behaviour. What, if anything, are they needed for? This question will be answered step-by-step. Let us recall, in any case, that Frege connects the mental images of a given person with his/her external activities. Although he rejects the equation "meaning = mental image", he nevertheless endorses a view of mental images that is far better than the views endorsed by most of those (generally Cartesian) theoreticians who accept this equation.

Let us again consider the tripartite diagram connected with the sentence (1), namely cat $\&$ arrow \& sack. If meaning is use, and not mental image, what is then the relation of this diagram to meaning? And what is the meaning of (1)? Now the meaning of (1) consists in the fact that if the speaker uses (1) correctly, s/he asserts that the situation described by the diagram obtains in extralinguistic reality, regardless of what (if anything) is going on either in his/her mind or in the hearer's mind. Most likely there is something going on. But this question is different from the question concerning the meaning of (1).

In terms of the "language - mind - reality" trichotomy, the psychologistic meaningconception reduces language to (linguistic) form and identifies meaning (= semantics) with mind (= psychology), whereas the social-conventional conception equates language with form-cum-meaning, keeping semantics apart from psychology. Thus, acceptance of linguistic (= semantic) vs. non-linguistic (= psychological) categorization seems to be a reliable criterion for the social-conventional meaning conception.

This is the position endorsed, for instance, by all contributions to Bohnemeyer \& Pedersen (2011), a volume predicated on the contrast between linguistics and psychology (cf. pp. 2-7). Depending on the case at hand, to be sure, the distance between semantic and cognitive categories may be considered either large or (nearly) nonexistent. For instance, while both Givón (1991) and Pawley (2011) agree that English verbs (= A) and Kalam serial verb constructions $(=\mathrm{B})$ are semantically dissimilar, they disagree as to the proper cognitive interpretation of this fact. For Givón, A and B are cognitively similar, which entails that languages, instead of directly expressing cognition, just exhibit some sort of surface variation. For Pawley, by contrast, A and B are cognitively dissimilar, which entails that linguistic/semantic differences reflect cognitive ones.

\section{Intuitions about norms/conventions vs. introspections}

\subsection{The normative vs. non-normative divide}

The phenomenon of linguistic normativity can be illustrated with a couple of concrete examples.

(6) This artery branches just below the elbow.

(7) *This artery branches just between the elbow.

Example (6) is a correct English sentence whereas (7) is incorrect; whoever utters (7) commits a mistake. Why? Because there is a norm that determines the use of between: it is correct to apply it to two or more things ("There was a lot of animosity between Mary and John and ...") 
whereas it is incorrect to apply it to one thing only (* "There was a lot of animosity between Mary").

In an analysis of (6), Langacker (1987, p. 175) states that "one mentally traces downward the artery. ... Summary scanning is involved". But let us assume that a given speaker either fails to perform this mental scanning or performs a different one. Has $\mathrm{s} / \mathrm{he}$ committed a mistake? No, because a mistake can be recognized for what it is only by virtue of public or intersubjective criteria, and there are no such criteria for the occurrence of mental scanning, or of mental imagery more generally (cf. Itkonen, 2008b, p. 24-25).

We know that (6) is a correct sentence of English, but we merely assume that whoever utters (6) performs a mental scanning as here described. We are clearly dealing with two distinct types of phenomena, which is why they have to be described by different terms. We say that the correctness of (6) and the incorrectness of (7) are known on the basis of (linguistic) intuition, whereas the occurrence of mental scanning in connection with (6) is assumed on the basis of introspection. As for the difference between introspection and observation (= perception), it consists in the fact that the latter, in using one of the five (principal) senses, pertains to external reality, whereas the former pertains to internal reality, i.e. the content of consciousness. There is a fundamental gap between introspection and intuition. Yet part of it can be filled by postulating an ascent from the former to the latter, with empathy functioning as a sort of half-way-house between the two: empathy is vicarious introspection while intuition is conventionalized empathy (cf. Itkonen, 2008b, pp. 25-27; 2013b, pp. 58-60).

In spite of its importance, the "intuition vs. introspection" distinction is not as well known as it deserves to be. Let us add the following clarification: "Whether a person experiences algebra as dreadfully boring or deeply satisfying is irrelevant to considerations of her understanding the subject. It is the action of correctly solving for $x$ or $y$ and not one's experience of doing so that determines whether one understands some aspect of algebra" (Susswein \& Racine, 2008, p. 145; emphasis added).

"Correct vs. incorrect" (or more generally, "right vs. wrong") is the basic normative opposition. The notion of normativity was preliminarily introduced in Section 4 because it is impossible to characterize the "meaning is use" thesis without reference to those rules/norms in accordance with which language is used. In fact, Cognitive Grammar features the term convention which is synonymous with that if norm: "The grammar of a language represents a speaker's knowledge of linguistic convention" (Langacker 1987, p. 36). “... our goal is to properly characterize a speaker's knowledge of linguistic convention ... (1991b, p. 268).

But at the same time, as we saw earlier, meanings are conceptualizations, and a conceptualization is "the occurrence of a cognitive event". The same is true of sounds as well: "sounds are like other concepts" (Langacker 1987, p. 78). As we just saw in connection with (6-7), there can be nothing right or wrong about cognitive events, because there are no public criteria for deciding which events are right and which ones are wrong. Conventions determine what is right or wrong and do not apply to conceptualizations (either qua meanings or qua sounds). So what is the status of the notion of convention in a theory like Cognitive Grammar?

As can be seen from the following quotations, conventions apply, to utterances (= tokens) and corresponding sentences (= types) as is customary in linguistics: "In preference to the standard term "grammaticality" ... I will refer to an expression's degree of conventionality" (Langacker, 1987, p. 66). "Moreover, the set of categorizations provide an assessment of the expression's degree of well-formedness (or conventionality)" (Langacker, 2007, 430). To illustrate: "linguists have normally judged sentences like [8] to be ungrammatical" (1987, p. 37; emphasis added). 
(8) *I want me to be elected.

(9) I want to be elected.

Thus, the primary goal of grammatical analysis remains the same as it has been throughout the history of linguistics: to describe the properties of correct (as opposed to incorrect) sentences, primarily sentences constructed on the basis of the grammarian's own linguistic intuition. Apollonius Dyscolus, adumbrated by Plato and Aristotle, inaugurated this venerable tradition in the West (cf. Itkonen, 1991,: 5.1-2; 2013a. pp. 749-750, 757-758), and we are still doing the same thing. This is also the basis for each and every psycholinguistic hypothesis (cf. 10.4, 11.1).

Let us add some confirmation: "It is only when the distortions are drastic enough ... that an expression is judged as being deviant" (Langacker, 2007, p. 430; emphasis added). Once again, notice that those entities that are being judged as deviant are not mental scannings or any other cognitive events, but good old-fashioned sentences in the Plato-AristotleApollonius tradition. Speaking of "expressions" instead of sentences does not change this fact.

It is on the basis of conventions that sentences are judged as non-deviant (= correct) or deviant (= incorrect). Thus, conventions perform the same duty in Cognitive Grammar as norms or rules do elsewhere. It is in the same sense that Clark (1996: 75-76), for instance, uses the term convention. To sort out the situation, we could avail ourselves of the dichotomy introduced in Section 4. Langacker claims to endorse the "meaning is image" position, but most of the time he in fact endorses the "meaning is use" position, which gives him the solid traditional basis on which to erect his descriptive apparatus. ${ }^{6}$

\subsection{The notion of norm/convention exemplified}

The following objection may arise: Perhaps there is no way to genuinely know cognitive events. But why should we think that norms/conventions are any different? Let us answer this objection. To begin with, consider the Latin sentences in (10-11).

\begin{tabular}{|c|c|c|c|}
\hline (10) & $\begin{array}{l}\text { Cogit-o } \\
\text { think-1p.sg }\end{array}$ & $\begin{array}{l}\text { ergo } \\
\text { therefore }\end{array}$ & $\begin{array}{l}\text { sum. } \\
\text { be.1p.sg }\end{array}$ \\
\hline & 'I think, ther & I am' & \\
\hline & $\begin{array}{l}\text { Canta-s } \\
\text { sing-2p.sg }\end{array}$ & $\begin{array}{l}\text { ergo } \\
\text { therefore }\end{array}$ & $\begin{array}{l}\text { salta-t } \\
\text { dance-3p.sg }\end{array}$ \\
\hline
\end{tabular}

Descartes is famous for having uttered (10). Did he know what he was saying? Did he know that the meaning of (10) is 'I think, therefore I am', and not, for instance, 'You are singing, therefore s/he is dancing'? More precisely, did he know those rules/norms/conventions of Latin that make (10) what it is and eo ipso make it different from (11)? And what are these rules?

First, there are rules which link forms (A) with meanings (B), for instance: $(\mathrm{A})=$ cogit-, ergo, sum, cant-, salt-, -o, - $s$, - $t$ vs. (B) = 'to think', 'therefore', 'I am', 'to sing', 'to dance', '1p.sg', '2p.sg', '3p.sg'. Second, there are rules which combine meaningful forms to produce

\footnotetext{
${ }^{6}$ The disentangling of these relationships has not been made any easier by sweeping statements like the following: "Meaning is ... defined as encompassing any kind of mental experience: (i) ...(ii) ... (iii) ... and (iv) full apprehension of the physical, linguistic, social, and cultural context" (2007, p. 431; emphasis added). Taken literally, this means that the entire universe, down to its last detail, must be taken into account, which amounts to a reductio ad absurdum.
} 
larger meaningful wholes, for instance: cogit- ('to think') $+-o$ ('1p.sg') $\rightarrow$ cogito ('I think'), etc. Clark (1996, p. 76) formulates exact counterparts for these two types of rules.

But did Descartes know these rules? Yes! How can I be so sure? Because otherwise, when intending to express the meaning 'I think, therefore I am', he would not have uttered Cogito ergo sum, but rather Cantas ergo saltat, or any other random sentence from among the infinitely many logically possible sentences of Latin or of some other language or of no language at all. Besides, Descartes could not have been very different from me; and I know such rules; and I also know that every normal person knows, or at least can come to know, such rules.

It is important to realize that rules of language, as I have formulated them here, are of pretheoretical nature. Taken together, they constitute what Chomsky $(1965$, p. 20) calls "the enormous mass of unquestionable data concerning the linguistic intuition of the native speaker". Knowing each of the above rules separately does not entail knowing how their totality (conceptualized e.g. as the entire verb system of Latin) should be theoretically described. Putnam (1981) expresses the same insight as follows: "I am inclined to think that the fact of speaker's privileged access [ $=$ linguistic intuition] does not extend to generalizations about correctness and incorrectness" (p. 110; original emphasis).

The "pretheoretical vs. theoretical" distinction was already the cornerstone of my 1974 dissertation. (At the time, I preferred the term atheoretical to pretheoretical.) Many people fail to see the point. During the last 40 years I have often encountered the following objection: "If the rules of language are known, there is nothing left for the grammarian to do!" This is my answer: All members of the Brahmanic caste who were Pānini's contemporaries knew the rules of Sanskrit as well as he did, but only he was able to compose (N.B. not write) the grammar that bears his name. Once the rules are known, everything still remains to be done.

Sentence (10) is the culmination point of the Cartesian doubt. Descartes wanted to find out if he could doubt literally everything, and at one point he thought that he could even doubt the truths of arithmetic. He finally arrived at the conclusion that there was only one thing that he could not doubt, namely his own self-awareness. He thought that he saw light and felt warmth, but maybe he was being misled by some evil spirit into thinking so. Yet he could not be mistaken about having these (perhaps mistaken) sense-impressions, i.e. about his own existence as a person capable of having sense-impressions. It is this certainty that he expressed by (10), which should accordingly be translated as "I have self-awareness, therefore I exist" (cf. Itkonen, 1978, p. 318, n. 39).

But Descartes was wrong. There was one thing of which he was so certain that he could not even think of doubting it. What was it? It was the (rule-governed) meanings of whatever he said. He was so certain of the meaning of (10) that it did not enter his otherwise inquisitive mind to doubt that maybe he was mistaking the meaning of (10) for that of, e.g., (11). By Descartes' standards, (pretheoretical) knowledge of language is more certain than knowledge of arithmetic. We owe this marvellous insight to Kenny (1975, p. 205).

Wittgenstein describes what it would be like to live without this certainty: "no one is surprised that we do not merely surmise the meaning of our words" $(1969, \S 523)$. "I should stand before an abyss if I wanted so much as to try doubting their meanings ..." (\$370). Professional linguists react with disbelief to such protestations of certainty. Eugenio Coseriu is an exception: "Dennoch ist in jedem Sprecher ... ein klares und sicheres Wissen" (= "And yet there is clear and certain knowledge in every speaker") (1975 [1958], p. 50; cf. López Serena 2009; Itkonen 2011c). 


\section{Conscious, unconscious, and neurological}

The central role of consciousness in linguistics has been consistently emphasized by Wallace Chafe and Leonard Talmy (cf. Itkonen, 2008b, pp. 17-21). For both of them, consciousness equals a state or process that can be accessed by "introspection". According to Chafe (1994, p. 12), introspection applies to "meanings, mental imagery, emotions", while he nowadays thinks that the most important function of introspection is to capture the "thoughts" qualitatively different from, and prior to, the semantic structure of any particular language (Chafe, 2013, pp. 112-113) According to Talmy (2000, p. 4), it is only by means of introspection that both the content and the structure of consciousness can be grasped; "and meaning is located in conscious experience" (p. 5). Notice incidentally that both Chafe and Talmy conflate introspection and intuition. Notice also that meaning is accessible to, rather than located in, conscious experience.

The position of generative linguistics is the exact opposite: "we must avoid the temptation to assume some notion of 'accessibility to consciousness' with regard to mental states and their contents" (Chomsky, 1986, p. 230; Jackendoff, 2002, p. 28). ${ }^{7}$ It goes without saying that, as far as the actual descriptive practice is concerned, Chafe and Talmy are much closer to the truth. As linguists, Chomsky and Jackendoff too must have mental states which they are conscious of (even if their physicalist world-view forces them to deny this fact).

Menn et al. (2013) represent a position intermediate between the two preceding ones. For them, the role of consciousness is much smaller than for Chafe and Talmy, but nevertheless greater than for Chomsky and Jackendoff; for instance, the "strategies" of speaking are (largely) under conscious control. On the other hand, their strong commitment to the experimental method places them clearly apart from generative linguistics. For them, the analysis of conscious intuitions or introspections does not guarantee that the results represent the unconscious part of the mind as well. Such a guarantee can only be given by the experimental method. This is not empty talk. The argument of Menn et al. (2013) is entirely based on results of experimentation.

What is Langacker's position on this issue? He carries out semantic analysis in exactly the same way as Chafe and Talmy. However, the influence of the physicalist Zeitgeist makes him utter statements divorced from his own descriptive practice: "Mind is neurological activity" (1987, p. 162; also 2007, p. 424). Furthermore, while conceptualization is the subject matter of semantic analysis, "it is not itself the object of contemplation" (2007, p. 431): "Only as a special case, and to a very limited extent, can we [consciously] monitor our own conceptualizing activity" (p. 451, n. 13). This statement appears to rule out both intuition and introspection as sources of data for semantic analysis.

The irrelevance of intuition/introspection is incontestable if the meanings of words and sentences are identified with conceptualizations understood as event tokens that occur in the human mind at the very moment when these words or sentences are either uttered or heard: "Meaning is something that occurs in the interlocutors' heads at the point of language use" (Croft, 2000, p. 111). Intuition and introspection remain just as irrelevant if meanings are identified with event types abstracted from (unconscious) event tokens. Both interpretations are incompatible with how Langacker and Croft themselves analyze meanings.

It is surprising that (as far as I can see) the inconsistency of Langacker's and Croft's position has escaped general notice. Because those cognitive events that they speak about

\footnotetext{
${ }^{7}$ Significantly, Chomsky and Jackendoff are just repeating what J.B. Watson, the father of Behaviourism, claimed in his first manifesto in 1913: "psychology must discard all reference to consciousness" (quoted from Mundle, 1970, p. 122). No wonder that "the difference between TG-type [= generativist] psychology and behaviourism is a difference not in kind, but in degree" (Itkonen, 1978, p. 114).
} 
(either per se or as a basis for abstraction) last only a fraction of a second, it is quite impossible that the speaker/hearer could become conscious of them. On the other hand, semantic analysis (as it has been carried out for more than 2000 years) is based precisely on what the analyst is conscious of. (Let us recall Talmy's dictum: "Meaning is located in conscious experience.") Hence, the basic assumption must be wrong: Meaning is not (and cannot be) conceptualization. How has this confusion come about?

The answer, already anticipated in previous sections, is as follows. Langacker and Croft think that they are speaking about unconscious cognitive events $(=\mathrm{A})$, but in reality they are speaking about norms accessible to conscious intuition (= B). A has only a split-second existence whereas B exists for years or even decades. This is why semantic analysis, instead of being tied to any particular moment, can be carried out at leisure.

Consider again (1), our first example. During the last 30 years or so, thousands of different cognitive events have occurred concerning (1), most of which are irreparably lost, having left no memory or trace. But the (literal) meaning of (1) has remained exactly the same during all this time; and there is no reason why the situation should be any different in one hundred years. This is the basic fact which, first and foremost, any metatheory of semantics must explain. The "meaning is use" position explains it without the slightest difficulty whereas the "meaning is image" position is utterly unable to do so.

It is not only the case that investigation of meaning-as-use has been mistaken for investigation of meaning-as-image, but also that investigation of what is conscious has been mistaken for investigation of what is unconscious. Generative linguistics in general ignores processing, but otherwise it commits the same mistake. It could have been avoided by enhanced self-reflection, i.e. by simply attending to what one is actually doing.

What are the mutual relations between conscious, unconscious, and neurological? This is of course a vast and difficult question, but it is nevertheless possible to give at least some clues about what the general answer is likely to be. According to Neisser (1976, p. 7), the fundamental tenets of cognitive science "are surprisingly like those of the nineteenth century introspective psychology, though without introspection itself'. Thus, both the structure and the functioning of the unconscious mind are assumed to be analogous to those of the conscious mind, even if the contents may be different (cf. Itkonen, 2005a, pp. 132-133). In fact Hermann Paul and Sigmund Freud shared the same assumption (pp. 224-225).

The conscious vs. unconscious divide prompts us to define more narrowly the notion of "mental". It makes sense to assume that the domain of what is mental is ontologically homogeneous. But it is heterogeneous from the epistemological (or methodological) point of view insofar as introspection provides the access to what is conscious whereas the unconscious has to be hypothesized about by means of observation-cum-experimentation (complemented by flashes of empathizing).

Today it is fashionable to identify mental with neurological, as we have seen. This position is summarized by the expression "mind/brain". I think this is a mistake. Mental activity is governed by rationality, whether conscious or unconscious; and unconscious rationality in turn presupposes the existence of unconscious goals and of unconscious beliefs (about means adequate to goals) (cf. Itkonen, 1983, pp. 185-188; 2013b, pp. 54-58). By contrast, neurological activity is automatic to the point of not being governed by rationality. Priming, as investigated by psycholinguists, "is a change in the level of activation of a particular neural structure [B] due to the automatic spreading of activation from a neural structure [A] that handles related information [i.e. information related to that handled by B], or to the maintenance of activation in a particular neural structure [C] persisting long enough to affect a later action carried out by that structure [C]" (Menn et al., 2013, pp. 217). The authors adduce many examples to show that, as far as the efficiency of communication is 
concerned, priming can be either beneficial or harmful, i.e. either rational or irrational. No doubt these activities too have their mental counterparts, but their (neurological) basis is in any case different from the (rational) means-end configuration that governs the activities of the (conscious and unconscious) mind.

Pickering \& Branigan (1999, pp. 136-137) offer two alternative interpretations: either priming is an automatic result of speech processing (as just suggested) or it too can be given a functional explanation: "syntactic priming facilitates the use of dialogue" (because one interlocutor is inclined to imitate constructions used by the other). These interpretations can be harmonized in the following way. Syntactic priming is based on neurological functionality (rather than, literally, rationality): energy must be saved. This works in simple cases, i.e. cases that are primary from the evolutionary point of view, but it becomes harmful in more advanced (or "sophisticated") cases of communication. Hence, it is a sort of "relic", still in part functionally viable. Indeed, it could retain a memory of the communal origin of language: according to one theory, pre-language was a collective performance similar to singing in choir (cf. Itkonen, 2005a, pp. 149-150).

The distinction between mental vs. neurological, or mind vs. brain, as here envisaged, is further supported by the following type of evidence. There are (at least) two qualitatively different ways to cause people to act involuntarily, namely post-hypnotic suggestion and stimulation of the brain. In the former case, when people make odd movements with their hands, they rationalize what happens, by telling themselves "I wanted to do it". But in the latter case, they experience their body as external to themselves (i.e. to their mind): "I could not control my hands". Koestler (1967) offers a nice summary: "One is tempted to say that the hypnotist imposes his will on the subject's mind - the surgeon merely on his brain" (p. 204).

As was mentioned above, Menn et al. (2013) leave some room for conscious strategies, but in emphasizing the primacy of experimentation they seem to be saying - and occasionally say in fact (e.g. on pp. 210-211) - that processes representative of genuine psychological reality are necessarily located below the level of consciousness. To my mind, this amounts to restricting the scope of psychological reality to an excessive degree. It would be unreasonable to doubt that e.g. the processes of reanalysis and extension involved in grammaticalization are psychologically real, even if their existence has not been experimentally validated (cf. Itkonen 2002). In the same vein, Haiman (1985, pp. 260-261) notes that iconicity and economy are "relatively accessible to conscious observation" and thus qualify as "conscious mechanisms". And of course, it should not be forgotten that most of the reasons for our everyday actions (although not as many as we would like to think) are thoroughly conscious goals and beliefs; and being causally effective, they must be psychologically real as well. ${ }^{8}$

Let us summarize the mutual relations of mind, brain, and behaviour, in terms of four distinct types of primacy, as formulated by von Wright (1998, p. 16): mental is epistemically primary vis-à-vis neurological; neurological is causally primary vis-à-vis behavioural; behavioural is semantically primary vis-à-vis mental (= "an inner process is in need of outward criteria"). The term causal is used here in a very restricted sense, given that "rational [goal-belief] explanations are conceptually primary vis-à-vis neurological or behavioural, i.e. causal, explanations" (p. 12; cf. here Sect. 14).

\footnotetext{
${ }^{8}$ An up-to-date account of the relevance of consciousness for language is given by Zlatev (2008a, 2008b, 2010).
} 
Public Journal of Semiotics 7 (1)

\section{Ontological levels}

To recapitulate our argument from the previous sections: Meaning is use, and use is identical with a set (or system) of norms (of acting). How do norms exist? A good preliminary answer results from accepting Popper's (1972) rather traditional view of three ontological levels or "worlds": world-3 is social-normative, world-2 is mental, and world-1 is biological/physical. The higher worlds presuppose, but cannot be reduced to, the lower ones. An analogous multilevel ontology has been endorsed e.g. by Bechtel \& Abrahamsen (1991, pp. 256-261) and more recently by Levinson (2006). The Popperian ontology has been applied to linguistics by Itkonen $(1981 \mathrm{a}, 1983)$ and Katz $(1981,1985)$, both of whom add that each of the three worlds has its characteristic act of knowledge, namely intuition, introspection, and observation (= sense-perception). Since then, the same overall conception has been endorsed e.g. by Carr (1990) and Dahl (2004, pp. 66-67), and a similar one by Harder (1999). A good summary has been presented by Zlatev (2007, pp. 322-326).

The results of Section 6 make it mandatory to add a couple of qualifications. First, from the ontological point of view, it is plausible to regard the mind qua world-2 as a homogeneous domain governed by rationality. From the epistemological point of view, however, the mind is divided into two: the conscious part is accessible to introspection, whereas the unconscious one is hypothesized about on the basis of observation/experimentation. (Of course, this boundary is always in flux.) Second, world-1, to be investigated by means of observation/experimentation, is homogeneous from the epistemological point of view, but not from the ontological point of view: neurological, but not physical, phenomena may be sensibly characterized as either "functional" or "non-functional".

The foregoing entails that insofar as each language, exemplified by its (in)correct sentences, is taken to exemplify world-3, linguistics is primarily an intuitional science. Katz (1985, p. 15, n. 46) notes that apart from himself, this view has been defended e.g. by Ringen (1975) and Itkonen (1981a). This list remains incomplete as long as Kac $(1974,1980)$ is not mentioned as well. The notion of intuitional science was definitively established by Arthur Pap in his forgotten classic Semantics and Necessary Truth (1958).

What does it mean to say that norms are inhabitants of world-3? It is unsatisfactory to leave this question open (as is too often done). My answer, based on the notion of convention developed by Lewis (1969), is that norms exist as objects of common knowledge (cf. Itkonen, 1978, pp 122-131, 2008a, pp. 288-291). The same position is represented e.g. by Clark (1996, pp. 93-96) with his notion of common ground and by Zlatev (2008c, pp. 215-221) with his notion of third-order mentality. It needs to be added, however, that common knowledge as such is not enough but must be more narrowly defined as normative common knowledge: it is commonly known that triangles are, and ought to be, called triangles. There have been persistent attempts to define norms in some non-normative terms, e.g. in terms of either speaker intentions or hearer expectations. But if these are incorrect, they are of no use; only correct intentions or expectations will do. This means of course that normativity cannot be eliminated (cf. Itkonen, 1978, pp. 182-186, 1983, pp. 167-168).

There are no causal relations in world-3. Therefore Wittgenstein as a philosopher is fully justified to disregard worlds-2\& 1 and to concentrate on world-3: "Our problem is not a causal but a conceptual one" (1958, p. 203). Hermann Paul (1975 [1880], p. 24) expresses the same insight by claiming that causal relations are to be found only in diachronic-cumpsychological data, not in the data of (synchronic) "descriptive" grammars: "zwischen Abstraktionen gibt es überhaupt keinen Kausalnexus" (= "there is no causal connection at all between abstractions"). It is easy to see that world-3 corresponds to Saussure-type langue whereas linguistic behaviour or parole is more complex: as a spatio-temporal phenomenon, it 
belongs to world-1; being permeated by psychological states and processes, it belongs to world-2; and qua exemplification of langue, it also partakes of world-3. Taken as a whole, linguistics investigates not just the non-causal realm of langue, but also the causal realm of parole (cf. Itkonen 1983).

There may be an inclination to brush aside all these issues as "too philosophical", but in reality every linguist must face them sooner or later. This is confirmed e.g. by Fillmore (1971, pp. 273-275): "The mentalist definition [of meaning] is of no use to anybody who wants to know whether he correctly understands some linguistic form, if only for the reason that there is no way of knowing whether the images [or concepts or ideas] that he has in his mind when he produces or encounters the form are shared by his interlocutors." Now, if the mentalist/psychologistic meaning conception is "of no use", what should it be replaced with? Expectedly, Fillmore recommends "the use theory of meaning" (ibidem), just as I have done in what precedes.

It is surprising that for example Langacker (1987, p. 156) cannot conceive of any alternative to psychologism pure and simple. If meaning is not conceptualization, "what else could it possibly be?" As we have seen one way to answer his question is that meaning is use.

\section{The ambiguity of "concept(ualization)"}

\subsection{World-3 semantics vs. world-2 semantics}

The preceding discussion has been tainted by an unfortunate ambiguity of the term concept(ualization); but now that different ontological levels have been clearly distinguished from each other, we are in a position to squarely face the issue. To put it starkly, philosophy and psychology regard concepts as inhabitants of world-3 and world-2, respectively. Linguistics vacillates between these two options.

Let us start with a quotation from Pap (1958): "The proposition, e.g., that all concepts of kinship relations that happen to be meanings of predicates of the English language are definable in terms of just the concepts 'male', 'female', and 'parent' is knowable a priori, by reflecting on concepts" (p. 274; emphasis added). This brief passage manages to express several important truths. The equation "concept $=$ meaning" is taken for granted in philosophical analysis; meaning has nothing to do with psychology; semantics is basically (though not entirely) the same in philosophy and in linguistics; and, at least in the "core area" of semantics, results are achieved just by means of intuition-cum-reflection.

Let us try to elucidate the process of semantic analysis à la Pap. How do we know that the kinship relations in English can be defined with just three semantic primitives (or "components")? Let us consider the following implications:

(12) If A is B's father, then A is male.

(13) If A is B's father, then A is B's parent.

(14) If $\mathrm{B}$ is $\mathrm{A}$ 's daughter, then $\mathrm{B}$ is female.

First, we elicit the three components by means of sentences like (12-14); and second, we go through the kinship terms one by one (= mother, brother, grandfather, uncle, aunt, cousin, etc.) to check that no other components are needed. But what, exactly, does "eliciting" mean in the present context? It is based on the presence of conceptual necessity between the antecedent and the consequent in each of (12-14). Necessarily true implications like (12-14) are called entailments. Necessity and possibility are inter-definable, as shown by the synonymy of (15) and (16). 
(15) Sentence (13) is necessarily true.

(16) It is not possible that A is B's father and that A is not B's parent.

It follows that "parent" must be part of the meaning of father, and likewise for the other components and the other kinship terms. "Being part of" should be taken literally insofar as the concept that occurs in the antecedent contains the one that occurs in the consequent. ${ }^{9}$

Now we are in a position to grasp the essence of philosophical/semantic analysis, as suggested by Pap in the following, as well as in the very title Semantics and Necessary Truth:

\begin{abstract}
Yet, since it is only by means of modal judgments that we can clarify concepts - e.g. "is it logically possible that a man should be entirely devoid of reasoning ability?" we ask, in order to make clear to ourselves the meaning of 'man' - faith in mutual understanding of basic modal terms is indeed an indispensable presupposition of all analytic philosophy. To him who does not grasp the sense of 'possible' in which the existence of immortal men is possible yet the existence of round squares not possible, no analytic philosophy can be taught (Pap, 1958, pp. 422; second emphasis added).
\end{abstract}

Let us add some confirmation: "In learning the meaning of words [like father and daughter] we in effect learn certain simple analytic truths [like (12-14)]; for these truths are simple in this way, that knowing them to be [necessarily] true is a necessary condition of understanding their meaning" (Edgley, 1970, p. 25). There is an important difference between (12-14) and sentences like If $A$ is $B$ 's father, then $A$ is healthy, If $A$ is $B$ 's father, then $A$ is taller than $B$, and If $B$ is $A$ 's daughter, then $B$ is fond of $A$. It is natural (though not imperative) to identify it with the analytic vs synthetic distinction (understood either as absolute or as gradual; cf. 11.4). To paraphrase Pap, to him or her who does not grasp this, no semantics can be taught.

How do we become aware of necessary truth (or conceptual necessity)? By means of intuition, pure and simple. Those who think that this is not enough commit a serious mistake, as Pap notes in the very last sentence of his monumental work: "The distrust of the 'intuitional' basis of analytic philosophy, therefore, is rooted in nothing less than an imperfect understanding of scientific method - in the broad sense of 'scientific' in which analytic philosophy can be scientific" (p. 422).

All this makes it impossible to maintain the mentalist "meaning is image" conception consistently. Claims like the following one, for instance, admit only of a (non-psychological) world-3 reading: "... father fully conveys the concepts [MALE] and [PARENT] ..." (Langacker, 1987, p. 293; similarly p. 462). First, we witness here genuine vacillation between world-3 and world-2 interpretations. Second, from the methodological point of view, this is a step backwards vis-à-vis Pap-type semantics: "the concept of entailment (and the related concepts of self-contradiction and logical incompatibility) is the primary tool by means of which analytic philosophers undertake to analyse concepts ...It is chiefly by means of intuitive judgments of entailment that the 'explicandum' of a given explication is identified" (Pap, 1958, pp. 92-93; emphasis added). Crucial information is lost when " $\mathrm{X}$ entails $\mathrm{Y}$ " is replaced by "X conveys Y".

To avoid confusions, we should use numbers borrowed from the Popperian ontology: concept(ualization)-3 vs. concept(ualization)-2. The dichotomy at issue has been pinpointed by Wittgenstein: "We are not analyzing a phenomenon (e.g. a thought) but a concept [= concept-3] (e.g. that of thinking), and therefore the use of a word" $(1958, \S 383)$. More detailed examples will be given in Section 10.

\footnotetext{
${ }^{9}$ Given the possibility of sex-change operations, (12) may have to be replaced by (12') If $A$ is $B$ 's father, then $A$ has once been male, and analogously for (14) (cf. Sampson, 1980, pp. 63-67).
} 
Predictably, there have also been attempts to establish some sort of world-1 semantics. The gist of those that I am aware of consists of programmatic statements to the effect that it is possible, in principle, to reformulate the claims of world-3 semantics in physical terms.

\subsection{Varieties of world-3 semantics}

The subject matter of traditional semantics belongs to world-3. This is what Johnson (1987) and Lakoff (1987) call "Objectivist Semantics", epitomized in its possible-worlds version. Their misgivings are shared by Langacker (1991b), because this type of semantics supposedly "seeks an objective characterization of meaning independent of human conceptualization" (p. 50). This characterization, however, is not accurate.

Hughes and Cresswell (1972, pp. 77-78) point out that "the power of conceiving" lies at the very heart of possible-worlds semantics. Being determined by "the constitution of the human mind and the human body" (emphasis added), conceptualization - viewed historically - produces asymmetrical relations between different (possible) worlds. As they see it, it is possible for people living today to imagine a world without telephones whereas it was impossible for people who lived 200 years ago to imagine (in every graphic detail) a world with telephones. Some people quibble with this claim, but it would be silly to deny that the attitude we adopt vis-à-vis the past is different from the one we adopt vis-à-vis the future. On reflection, this difference can be explicated as a modal asymmetry formalized by possibleworlds semantics. Thus, contrary to a wide-spread misunderstanding, such notions as conceptualization, imagination, and embodiment are indispensable, rather than antagonistic, to "Objectivist Semantics". Of course, this is embodiment at a rather high level of abstraction.

Moreover, it is the express purpose of possible-worlds semantics, as part of epistemic logic, to capture the content of such cognitive processes and/or states as perception, memory, intention, belief, and knowledge. This type of formalization is meant to constitute an explanatory framework which in each particular case "elucidates a way of using language insofar as this use is determined only by one main purpose" (Hintikka, 1969, p. 6; emphasis added; for discussion, cf. Itkonen, 1978, pp. 288-293). Thus, meaning-as-use and meaning-aspossible-worlds can be seen as variants of world-3 semantics, with differential emphasis on the need for formalization.

Let it be added that possible-worlds semantics is flexible enough to be interpreted as a type of world-2 semantics as well. Such a research program has been implemented by Kroy (1976). As he sees it, "on the one hand, mentalism lacks an exact (or 'scientific') formulation, and modal logic is there just to fill this gap; on the other, modal logic lacks a meaningful interpretation, and mentalism is there just to fill this gap. ... Now, it is precisely as a formal theory of imagination that Kroy wants possible-worlds semantics to be understood" (Itkonen, 1983, p. 304).

Up to now, I have defined philosophical semantics as conceptual-3 analysis, equating it with traditional linguistic semantics. But this view cannot be accepted as it stands. Prima facie at least, linguistics describes existing meanings the best it can, but without trying to change them. By contrast, philosophy has a traditional interest in enabling people to think better, which may involve changing some of the existing meanings. This already became evident in Pap's (1958, p. 422) remark that it is the philosopher's job to clarify concepts.

So-called ordinary-language philosophers were anxious to delete this prescriptive element from what they were doing. Searle (1969, Ch. 6) argues forcefully that such an attitude is bound to produce philosophical platitudes. Therefore, from the philosophical point of view, meaning is not (nothing but) use, and Putnam (1981) agrees: 
Public Journal of Semiotics 7 (1)

\begin{abstract}
We cannot appeal to public norms to decide what is and what is not rationally argued and justified in philosophy. The claim which is still often heard that philosophy is 'conceptual analysis', that the concepts themselves determine what philosophical arguments are right, is, when combined with the doctrine that concepts are norms or rules underlying public linguistic practices, just a covert form of the claim ... that philosophical truth is ... as publicly demonstrable as scientific truth. Such a view seems to me to be simply unreasonable ... (pp. 111-112).
\end{abstract}

Interestingly, "meaning is use" turns out to be a better precept for linguistic analysis than for philosophical analysis: "The words and expressions, the use of which bewilders the philosopher, are so to speak in search of a meaning" (von Wright, 1963, p. 5).

We seem to have arrived at a clear-cut distinction, within world-3 semantics, between descriptive (= linguistic) vs. prescriptive (= philosophical) undertakings. But this is too crude. Surely there is some sense in which linguistic semantics too clarifies its own subject matter, even if it may be not be exactly the same sense in which philosophical semantics does so. A concrete example, due to Kahneman (2011), will be given in subsection 10.2.

\title{
9. Encyclopedic meaning
}

In most of cognitive semantics, the distinction between lexicon and encyclopedia is rejected (e.g. Geeraerts 2010). In one way, this is consistent with the meaning is use approach, as "[i]n natural languages knowledge of language is inseparable from knowledge about factual properties of the world ..." (Itkonen, 1969a, p. 233). On the other hand, there is a level of normative meaning as shown in examples (12-16), where factual matters become irrelevant: "Consequently the alleged independence of meaning from the world can only be accepted in the sense that given certain word- and sentence-meanings, certain relations between them are such that without any knowledge about either factual or hypothetical situations in the world it can be determined whether they hold or not" (Itkonen, 1970a, pp. 97).

In many versions of cognitive semantics the encyclopedic nature of lexical meanings is represented with the aid of domains. For instance the meaning of glass contains inter alia the following domains: "shape ... orientation ... function ... its role in the process of drinking ... material ... size ... cost, washing, storage, possibility of breaking during the meal, matching sets, methods of manufacture" (Langacker, 2007, p. 434-435). All these domains are further divided into subdomains. Let us focus on function: a glass contains some liquid, which necessitates defining "liquid" and distinguishing it from other types of matter; one drinks from a glass, and distinguishing drinking from eating necessitates an account of (human) digestion; a glass is grasped with a hand, which necessitates an account of the human body; but "body" becomes comprehensible only in contrast with "mind", which gives rise to a set of additional questions to be answered by the encyclopedic-semantic analysis: What is mind? Is there a soul in addition to the mind? (and if not, why not?) Do animals too have a mind? Manufacture in turn necessitates a historical account of how handicraft has been replaced (albeit not entirely) by industrial production, which requires taking a stand on the current status of the working class: Has automation rendered the class struggle obsolete? What comes after communism? Will the focus of global economy shift to the Far East? If not, why not?

Halfway through the previous paragraph, I started gradually to extend the scope of the original example. So much is clear, in any case, that an exhaustive analysis of the meaning of glass (or of any other word) necessitates taking literally everything into consideration. This means that at some point we have gone astray. It would have been more reasonable, to begin with, to follow Patañjali's (150 BC) general advice to delimit the data, as described by Itkonen (1991: 62): "If we wish to put in the description of a construction, i.e. in its abstract form, all the information that it conveys to us, this process will never end, because - due to 
the functioning of associations - the information conveyed by any given construction is in principle infinite."

Langacker (1987, p. 432) attemps to avert this danger by proposing to select from among the existing knowledge only the part that is conventionally accepted by the linguistic community. But distinguishing between $\mathrm{X}$ and $\mathrm{Y}$ presupposes knowledge of both $\mathrm{X}$ and $\mathrm{Y}$. Therefore a fully encyclopedic semantics comes surprisingly close to Bloomfield's (1933) meaning-conception: "In practice, we define the meaning of a linguistic form, whenever we can, in terms of some other science" (p. 140). Therefore, instead of describing the entire universe, the prudent strategy seems to be to extend the scope of semantic analysis in a stepby-step fashion, starting from the "core", i.e. grammatical meanings and necessary relations between word and sentence meanings.

How about the encyclopedic interpretation of verb meanings? The conceptual content of to admire is analyzed by Langacker (1987) in a way that does not differ at all from a traditional dictionary definition: "an experiential relationship, wherein a sentient creature entertains a positive mental attitude toward some other entity" (p. 435). This definition (which ignores self-admiration, in addition to conflating love, like and admire) seems to indicate that verbs are not as conducive to associations and/or inferences between bits of world knowledge as nouns are. But of course such notions as "attitude" and "positive" open the door wide open to musings about the universe at large.

\section{Comparing the different frameworks}

Two distinct notions of semantics have emerged by now: either intuition-based analysis of concepts determined by socially valid norms or experimental analysis of mental processing combined with encyclopedic analysis. This difference should produce corresponding differences in the description of (what looks like) one and the same subject matter. This section has an additional purpose, namely to show the ultimate (near-)unity of world-3 analysis, as exemplified by linguistics, logic, philosophy, and geometry.

\subsection{Inference and entailment}

Let us start with a maximally clear example. In the beginning of Section 4 we saw Langacker (1987, p. 113) claiming that mathematics is a mental construction subsumable under psychology. Therefore the same must be true of logic as well. But of course, formal logic and psychology of logic are two different things.

Inferences may be either deductive or inductive. Here we shall concentrate on the former. Let us consider the inference (17) and the corresponding inference schema (18), in which atomary sentences have been replaced by sentence-variables.

(a) If John is home, the lights are on.

(b) The lights are not on.

(c) Therefore John is not home.

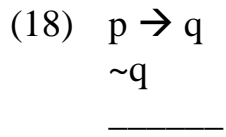

$\sim \mathrm{p}$

A logically binding or valid inference is characterized by the fact that the conclusion cannot be false if the premises are true. The validity of the schema (18), known as modus tollens, has been understood since antiquity (cf. Itkonen, 2013a, p. 754). If the premises and the conclusion are replaced, respectively, by the antecedent $A$ and the consequent $B,(18)$ is transformed into an implication if $A$, then $B$, yielding the following (sentence) formula:

$$
[(p \rightarrow q) \& \sim q] \rightarrow \sim p
$$


Informally, it is unexceptional to say that in (17a) the consequent (= "the lights are on") is "inferred" from the antecedent (= "John is home"). Technically, however, inferences must have the premise(s) vs. conclusion -structure of e.g. (17-18). Thus, (19) is not an inference, but a sentence (= implication). Inferences, unlike sentences, are not true or false but valid or non-valid. There are several ways to prove that (17-18) is (logically) valid while (19) is logically/necessarily true (cf. Itkonen, 2003a, pp. 16-21). A necessarily true implication is called an entailment (see 8.1 ). " $A$ entails $B$ " is synonymous with " $B$ follows logically from $A$ ". Entailments are based either on descriptive concepts, like (12-14), or on logical form, like (19). Necessary truths may or may not be entailments. (20), i.e. the law of (non-)contradiction, which Aristotle calls "the most certain principle of all", is a necessary truth but not, of course, an entailment. Generally speaking, "necessarily true" may be taken to be synonymous with "analytic", although there are complications (see 11.4). The negation of an analytic sentence is in turn a (self-)contradiction.

$$
\sim(p \& \sim p) \quad \text { "not-(p and not-p)" }
$$

Inferences can be interpreted either in non-processual or in processual terms. On the latter (more realistic) interpretation, they are a type of activity which follows the rules of (formal) logic. These are located in world-3. If anyone infers in violation of these rules, e.g. by reaching in (18) a conclusion different from $\sim p$, or no conclusion at all, (s)he commits a mistake. As far as the validity or non-validity of an inference is concerned, it is irrelevant what (if anything) goes on in the mind of the one who performs it (see 5.1).

Things are quite different in the psychology of logic. It does not investigate how people ought to infer, but how they infer as a matter of fact. Therefore it deals with world-2. Its data is characterized by ubiquitous variation, both between performances of different inferences by one and the same person and between performances of one and the same inference by different persons. Therefore descriptions adequate to this type of data must be of statistical nature, whereas - as is already evident from (18-19) - statistics is incompatible with (standard) formal logic. Differential performances are explained by a combination of distinct factors such as differences in the complexity of inferences, in the material contained in the premises, and in the logical ability of participants. Very elaborate explanations for statistical variation in logical behaviour have been provided e.g. by the theory of "mental models" developed by Johnson-Laird (1983) (cf. Itkonen, 2003a, pp. 152-162). Needless to say, there is no room for such explanations within formal logic.

There are no entries for necessary truth, logical inference, or entailment in the index of Geeraerts \& Cuyckens (2007), apart from a single entry for entailment, referring to this brief (and uncontroversial) passage: "metonymic links do not exist by conceptual necessity" (p. 241). Hence we must look elsewhere. What do we find? According to Sweetser (1990, pp. 6465), for instance, a cause-effect relationship obtains e.g. in (17) between the premises (a) \& (b) and the conclusion (c): there is an "epistemic force" which compels people to move from the former to the latter. This transition is assumed to take place in accordance with the PATH image schema.

This is somewhat disappointing in comparison with the results achieved within psychology of logic. First, the rich explanatory framework of mental models has been replaced by a reference to "epistemic force", which is just a virtus dormitiva type label for whatever it is that makes people move from premises to conclusions. Second, it is not explained why this "force" affects different people in quite different ways (as shown by the relevant statistics). Third, in more complex cases this "force" does not exist (outside the circle of professional 
logicians). Fourth, although psychology of logic primarily deals with actual inferences, i.e. with world-2 (as embodied in world-1), as a discipline it certainly presupposes knowledge of world-3 (as encoded in rules of formal logic): without such a background the notion of "(differential) logical ability" would not make sense. Indeed, "variation" between performances means how good or bad they are; and this is decided by reference to rules of formal logic. This aspect is evident all the time e.g. in Johnson-Laird (1983), but absent from Sweetser (1990).

Johnson (1987) too analyzes inferences on the basis of the PATH image schema: "Metaphorically we understand the process of reasoning as a form of motion along a path" ( $p$. 38). He gives (p. 64) the following example, where the notation has been modified so as to agree with Hughes \& Cresswell (1972) and, hence, also with Itkonen (2003a):

$$
\begin{aligned}
& \mathrm{Lp} \rightarrow \mathrm{p} \quad= \\
& \text { "If } p \text { is logically necessary, then } p \text { is true" (or more transparently: "if } p \text { is } \\
& \text { necessarily true, then } p \text { is true simpliciter") }
\end{aligned}
$$

As Johnson sees it, (21) illustrates the sense in which inferences are motivated or justified by the PATH schema: "The force of logic moves us from one propositional location to anotherforcing us to conclusions. ... If the force of logic operates to move you to a certain 'place', then you wind up in that place."

A few comments are now called for. First, (21) is a logical truth. The attempt to "explain" it by referring to "logical force" is defective because this is nothing but a virtus dormitiva type label similar to Sweetser's (1990) "epistemic force" (cf. above). Surely it is circular to explain logical behavior by logical force. Second, Johnson intends to analyze inferences, but (21) is an implication, not an inference: $p$ is a consequent, not a conclusion. Third, even on the most liberal interpretation of "inference", Johnson misuses this term. For instance, he regards (p. 40) the law of the excluded middle $p \vee \sim p$ as an "inference pattern", which it is not. Fourth, in connection with (valid) inferences like (18), it is appropriate to speak of "moving from one location to another" (i.e. from the premises to the conclusion). But it is inappropriate in connection with logical truths like (21). Rather, (21) is analogous to (22) and (23).

(22) If $p$ is true always, $p$ is true now.

(23) If A weighs 3 kilos, A weighs more than 2 kilos.

In other words, the one who utters (21-23) realizes or - more accurately - ought to realize that, on reflection, $\mathrm{s} /$ he has not moved at all but has remained in one and the same location. Why? Because the content of the consequent is contained in the content of the antecedent. If we must continue to speak of schemas, then the schema required by (21) is not PATH, but perhaps CONTAINER.

Fifth, and most importantly, the whole idea of accounting for logical truth or validity in terms of cognitive processing is mistaken. As we already saw in connection with mental models, in this domain there is no (logical) necessity, only statistical regularities. To think otherwise is the age-old defect of psychologism, and it is simply perpetuated here. The requisite cure has been offered, in different ways, by Peter Abaelard, Frege, Husserl, Wittgenstein, and others. 


\subsection{Knowledge}

Up to now, semantic/conceptual analysis has been exemplified by (12-14). The traditional definition of "knowledge" is intellectually more stimulating: "Knowledge is justified true belief" (cf. Pap, 1958, p. 295; Quinton, 1970, pp. 121-122; Itkonen, 1978, pp. 302-304). It is possible to elicit the three components of this definition by means of different types of entailments, as in (24-26).

(24) If A knew that $\mathrm{p}$, then $p$ was true.

(25) If A correctly guessed that $\mathrm{p}$, then A had a true belief concerning $p$, but A did not know that $\mathrm{p}$.

(26) If $\mathrm{A}$ believed that $\mathrm{p}$, when $p$ was highly probable and yet false, then $\mathrm{A}$ had a justified belief concerning $p$, but A did not know that $\mathrm{p}$.

Thus, neither "true belief" nor "justified belief" is in itself enough. Rather, the two have to be combined. As a result, we arrive at these meaning components: knowledge is a) true b) justified c) belief. This analysis is further supported by the correctness of (27-28) and the incorrectness of $\left(27^{\prime}-28^{\prime}\right)$ :

(27) A not only believed that $p, A$ actually knew that $p$.

(28) A not only guessed that $\mathrm{p}, \mathrm{A}$ actually knew that $\mathrm{p}$ (because $\mathrm{s} / \mathrm{he}$ was justified to believe that $\mathrm{p}$ ).

$\left(27^{\prime}\right) *$ A not only knew that $\mathrm{p}, \mathrm{A}$ actually believed that $\mathrm{p}$.

$\left(28^{\prime}\right) *$ A not only knew that $\mathrm{p}, \mathrm{A}$ actually guessed that $\mathrm{p}$.

The preceding analysis is confirmed by Kahneman (2011, p. 201): “In everyday language, we apply the word know only when what is known is true and can be shown to be true." Kahneman is annoyed by the fact that some people apply the word differently, as when they claim that they "knew well before it happened that the 2008 financial crisis was inevitable"; and he gives this verdict: "This is a misuse of an important concept" (emphasis added).

In principle, Kahneman agrees with my position: meaning is use; use is governed by norms; the presence of norms implies the ever-present possibility of mistakes; mistakes need to be corrected. But there may also be some room for variation, assuming that a semantic change is going on in the direction of relaxing the criteria for the use of the English verb know. On this interpretation, Kahneman gives us a glimpse of the prescriptive element in linguistic semantics (cf. 8.2).

With considerable effort, it is possible to imagine a counter-example to our definition, which then necessitates some additional fine-tuning (cf. Lehrer, 1974, p. 18-32). For all practical purposes, however, we may accept the definition as it stands. Still, its scope may not be unlimited. It contains the word/concept "belief", but Needham (1972) denies the universal validity of this concept, because many languages lack the corresponding word. It is easy to find cross-linguistic confirmation for Needham's claim. In Hua, for instance, the closest counterpart of the English verb to believe is the expression keta havi- ('hear one's ear', where $\phi$-keta $=$ '3p.sg-ear' + havi- = 'to hear'), followed by the exponent of the gerund in -gasi', "that most mysterious of all Hua forms" (Haiman, 1980, p. xi, pp. 456-457; also Itkonen, 2005b, pp. 92-93). More precisely, havi- = 'to hear' $+d$-keta $=$ 'my ear',$+k$-keta $=$ 'your.sg ear', $+\phi$-keta $=$ 'his/her ear', etc. The most natural translations are 'I think (that)', 'you.sg think (that)', 's/he thinks (that)', etc. 
To give another example, Wari' has a "verbalized sentence" construction which expresses 'to say'/'to think' by a lexical zero, i.e. the complement clause is followed by nothing but the subject clitic and optionally by the object clitic, schematically in (29).

$$
\text { "S"- } \phi \text {-he(-her) }=\text { "S" he says (to her) or thinks (of her) }
$$

This construction, called "highly unusual, perhaps unique" by Everett and Kern (1997, p. 355), is the closest equivalent of the verb to believe in Wari' (cf. also Itkonen, 2005b, pp. 176-178). Surely it would be wrong to simply claim that English, Hua, and Wari' share the same concept of "belief". This is also the gist of the ethnological data gathered by Needham (1972). If the definition of "knowledge" requires the concept of "belief", it follows that this definition cannot be universally valid. From the philosophical point of view, however, this is not a problem. It is enough to say that where "knowledge" fails to occur, it ought to occur.

In any case, the preceding definition of "knowledge" can be accepted, not only as a philosophical definition but also as a linguistic definition of the meaning of knowledge in a language like English. On this interpretation, meanings of course belong to world-3 and are, at least primarily, the subject matter of non-psychological and/or non-encyclopedic semantic analysis. What does the meaning of knowledge look like, when analyzed within cognitive semantics?

Mental predicates like to know are typically assigned to the category of epistemic modality, i.e. the modality concerned with degrees of probability (cf. Mortelmans, 2007, p. 870 ). According to the preliminary definition given by Nuyts (2001, p. 111), 'to know that p' $=$ 'to be convinced that p'; but he adds that it is difficult to draw the line between what is epistemic and what is evidential. In the absence of a fully explicit definition, it seems safe to assume that what Langacker (1987, p. 129-130) calls "optimal viewing arrangement" at least comes close to what he regards as knowledge. It is important to establish the identity of the cognitive process that obtains in such a situation: it is sense perception, i.e. the process which constitutes the very foundation of cognition: "Semantics cannot of course be described at once in its entirety. It is easiest - and probably necessary as well - to start from the simplest case, i.e. sense perception, and to proceed to the more complex cases only gradually" (Itkonen, 1969a, p. 230).

The definition given by Nuyts (2001) can be understood in two different ways. It remains within world-3 if the meanings of the two expressions to know and to be convinced are just thought to be compared in the same way as e.g. 'to fly' and 'to move through the air or space'. But if being convinced is thought to be a certain kind of mental state (based on a certain kind of evidence), then world-3 has been replaced by world-2. And Langacker's (1987) "optimal viewing arrangement" is clearly located within world-2, given that it describes a situation where a viewer perceives an object "sharply differentiated from its surroundings" (p. 129).

But fundamental questions still remain unanswered. It is difficult (in fact, impossible) to see how 'to know that p' can be adequately defined without any reference to the truth value of $p$. Langacker (1991a, p. 272) indeed admits as much when he notes that epistemic modality is characterized by the fact that "its sole import is to indicate the likelihood of the designated process". But truth and likelihood are problematic notions. Cognitive Grammar is not concerned with reality per se but with its different conceptualizations, and these vary from person to person, and are also known to do so, which entails that "any of these reality conceptions ... may be inconsistent and in error on many points" (Langacker, 1987, p. 114). It follows that either there is no truth at all or at most it is highly subjective. But the truth 
presupposed by our definition of "knowledge" must be objective. How do we arrive at objective truth?

Lakoff and Johnson (1980, p. 179) offer - with special emphasis - the following kind of experientialist (= anti-objectivist) definition of truth: We understand the statement A, on the one hand, and the situation $\mathrm{B}$ which A refers to, on the other, and A is true when "the understanding of $[\mathrm{A}]$ fits our understanding of $[\mathrm{B}]$ closely enough for our purposes". But this can mean anything at all! How about Lakoff and Johnson's (1980) own (very critical) statements concerning traditional semantics? No doubt they regard these statements as true for their own (subjective) purposes. I regard them as false, for my own purposes. If there are no objective criteria, we would descend into total relativism. To be sure, Lakoff and Johnson (1980) do make some gestures in the right direction: "Objectivity still involves rising above individual bias, whether in matters of knowledge or value" (p. 227). But how do we, exactly, "rise above individual bias"?

\subsection{Triangle}

How should a rectangle or triangle be described? This question may be understood in two distinct ways: the description pertains either to these figures as such or to how they are perceived (or drawn). In other words, geometry must be distinguished from psychology of geometry (cf. Itkonen, 1983, pp. 1-7).

In traditional plane geometry the triangle is described (or defined) as a "polygon of three sides and three angles", or more simply as "three-sided polygon" (which in turn presupposes prior acquaintance, by either ostension or definition, with the notions involved). The same definition may be taken in the linguistic sense as well, simply because it is the one that is typically given in dictionaries. The corresponding psychological description is incomparably more complex because it refers to no less than eight distinct processes: comparison, scanning, selection, abstraction, construal, imagery, transformation, rotation. All these processes are indeed contained in the (preliminary) description that Langacker (1987, Ch. 3) assigns to the meaning of triangle. This is required by his endorsement of encyclopedic semantics.

Our example illustrates Wittgenstein's “conceptual vs. causal” distinction (see Sect. 7). Geometry deals with the concept (i.e. concept-3) of triangle whereas psychology deals with cognitive processes that apply to triangles, and such processes have their causes and effects. Once again, we are faced with the fundamental ambiguity of the term concept. As far as logic, philosophy, and geometry are concerned, concepts-3 are objects of conscious intuition-cumreflection. In psychology, by contrast, concepts- 2 are subconscious, hypothetical entities postulated in order to (causally) explain observable behaviour. As noted before, linguistics deals either with concepts- 3 or with concepts- 2 or - inconsistently - with both at the same time. In my opinion, the term conceptual analysis should be understood in the former sense. But Langacker (1991b, p. ix), for instance, chooses to understand it in the latter, psychological sense.

The conceptual-3 (= non-causal) description is logically primary vis-à-vis the causal one: before we can describe how a triangle is perceived, we must know what a triangle is. It was the original purpose of my geometric examples to offer an analogy that should facilitate the proper understanding of linguistic research: before we can describe how the English relative clause is perceived or produced, we must know what the English relative clause is, to begin with.

More generally, we must distinguish between (intersubjective) language and (subjective) knowledge of language. In the tradition of generative linguistics, linguists do not describe English but "knowledge of English". Langacker agrees: "the grammar of a language 
represents a speaker's knowledge of linguistic convention" (1987, p. 36). But this is inaccurate. In order to describe the linguistic convention, we must of course know it. But what we qua grammarians describe is the convention tout court, not our knowledge of it, i.e. not the psychological mechanism that enables us to know it. For instance, we describe the convention according to which Dreieck means 'triangle' in German, not our knowledge of this convention. (Besides, what is our knowledge of this convention?)

This is exactly what Sapir (1921, p. 11) had in mind when he proposed to study language "as an institutional or cultural entity, leaving the organic and psychological mechanisms back of it as something to be taken for granted". In just the same way, we must know triangles in order to describe them, but what we describe are triangles as known by us, not our knowledge of triangles. Interestingly, there is a further analogy to what is going on in physics: "We do not choose reports about our own observational experiences, but rather reports about physical bodies which we have observed" (Popper, 1972 [1963], p. 267). This distinction may seem subtle but it is nevertheless a real and important one.

It is the express purpose of mainstream cognitive semantics to focus on precisely those "organic and psychological mechanisms" that Sapir was willing to disregard. But there is a logical order which one must follow: first the relative clause, then its perception and/or production; first the language, then its psychology.

Langacker (1987, Ch. 3) makes it perfectly clear that, for Cognitive Grammar, geometry does not just offer an analogy for linguistics. It is rather the case that the cognition of geometrical figures is literally part of cognitive linguistics, and - by implication - the same goes for any phenomena at all. Espousing such a strong version of encyclopedic semantics entails that linguistics is rapidly becoming an auxiliary science dependent on results achieved within other, more developed sciences. It is easy to see that linguists cannot rival professional psychologists and neurologists in comprehending e.g. the eight cognitive processes mentioned above, so all they can do is to offer popularized versions of what these other scholars have been doing. For years by now, we have witnessed the same thing happening in evolutionary theory where some linguists, as described by Johansson (2011) and Behme (2014), have been making valiant efforts to keep up with professional biologists. It is easy to find historical parallels. Due to its concern with rewriting rules, for instance, early generative theory was something like "mathematics for the uneducated".

\subsection{Pondering the implications}

Consider this quotation: "All of the last two decades of work in cognitive linguistics has radically changed our understanding of semantics" (Sweetser 1999: 133; emphasis added). How should we judge this glowing assessment?

The answer depends on what is meant by "radical change". In the natural sciences it means that a new theory has falsified the old one. It is vitally important to understand the simple truth that this is not the situation we have in semantics. No amount of psychological research can falsify those descriptions (= "dictionary definitions") that traditional semantics assigns to the meanings of triangle and knowledge, for instance. It seems fair to say that such descriptions concentrate on the (world-3) core of what is meant by these words. This core can be complemented ad libitum, but not falsified, by psychological (world-2) research.

Interestingly, Langacker (1987) agrees, at least implicitly. In the same context where he asserts the concepts [MALE] and [PARENT] to be "fully conveyed" by (though not equivalent to) father, he also notes that triangle is not strictly equivalent to three-sided polygon because the notion [POLYGON] is "considerably less prominent in triangle than in its periphrastic counterpart" (p. 293). Again, "the inclusion of the designated entity in a broader class of geometrical figures is highlighted by three-sided polygon, but remains latent 
in the case of triangle" (1991b, p. 10). Thus, 'three-sided polygon' remains the inescapable, unfalsifiable core of 'triangle' just as I have claimed it must. Now, do you think that this definition is too simple? No matter! You are free to refine it the best you can. But what you are not free to do is to reject (or ignore) it.

Our third example, i.e. inference-cum-entailment, represents a somewhat different type of case insofar as it involves formal logic. The attitudes that linguists and logicians have vis-àvis their respective data are certainly not identical (cf. Itkonen, 1978, pp. 48-54). Nevertheless, inferences performed in natural language can be understood only against the background of formal logic. This is true, in particular, of the psychology of logic as practiced by Johnson-Laird (1983). If his mental models are compared to what Sweetser (1990) has to say about inferences, there may indeed be reason to speak about a "radical change", but it is hardly a change for the better (cf. Itkonen, 2003a, pp. 152-162).

The reader may be excused for having thought that the alternatives "meaning is use" and "meaning is mental image" are nothing but philosophical hair-splitting. It turns out, however, that endorsing one or the other alternative has concrete implications about, or may even determine what kind of semantic analysis will be carried out. The former alternative justifies traditional semantics because it locates meanings at the level of norms, or in world-3. The latter alternative seems to justify restricting the analysis to individual psychology, or world-2.

The thesis "meaning is use" also justifies possible-worlds semantics because - as we have seen - it can be interpreted as describing the use of such words as possible, necessary, conceptualization, imagination, memory, etc. To be sure, doing so presupposes raising the level of abstraction, but this should not be a problem. The fact is, however, that problems often ensue from such situations, and quite unnecessarily so. For instance, the controversy over the descriptive categories employed in typological linguistics is entirely due to the fact that some participants erroneously assume that cross-linguistic comparison is carried out on one level of abstraction only (cf. Itkonen, 2011b).

What is the overall view of semantics that emerges from what precedes? The description must start from the analyst's own linguistic intuition. Depending on one's personal predilections, either no other data is needed or more and more diverse types of data are taken into account. A younger generation of cognitive semanticists increasingly favors methodological diversity (cf. Gonzalez-Marquez et al., 2007).

The latter can be made even more precise by considering the eye-tracking experiments on agreement reported in Vainio, Hyönä \& Pajunen $(2003,2008)$. It turns out that if, within a Finnish sentence context, two inflected words $(=\mathrm{ADJ}+\mathrm{N})$ are united by explicit agreement markers, they are read more rapidly than one inflected $\mathrm{N}$, which is totally unexpected. (By contrast, it is only to be expected that two words with agreement are read more rapidly than two words without agreement, as exemplified by an inflected $\mathrm{N}$ preceded by an uninflected ADJ.) These experiments are quite significant because they provide a functional explanation for the existence of agreement: instead of being redundant, as claimed by Haiman (1985, p. 164 ) and many others, it facilitates comprehension.

But what happens before? What do these experiments presuppose? First, the words involved must be chosen so as to be equally frequent, which requires the use of a sufficient large corpus. Second, there must not be any semantic or stylistic differences between the words, which is ascertained by the use of sufficiently detailed questionnaires to be filled by the participants. It is only after these preliminaries that the actual experiments are carried out. But before anything else, of course, it is the analyst's linguistic intuition that selects the possible candidate words, in the first place. Moreover, it is intuition which provides "certain universal editing rules to take care of stammering and false starts" (Labov, 1972, p. 203), rules 
that have to be applied to any would-be corpus. In other words, intuition constitutes a "normative filter" through which each and every corpus has to pass. Written corpora have their own editing rules.

Thus, we end up with the following temporal and logical hierarchy of descriptive methods where the items to the right presuppose those to the left (cf. Itkonen \& Pajunen, 2010, pp. 95-113; anticipated by Itkonen 1980).

$$
\text { intuition }<\text { corpus }<\text { questionnaire }<\text { experiment }
$$

In conclusion, many cognitive semantics analyses have firmly remained within world-3; they have just mistakenly been thought to be about world-2. It is the same fallacy that vitiates generative linguistics: autonomous linguistics is mistaken for psycholinguistics (cf. Kac, 1974, 1980). This also gives a new angle on the "radical change" announced by Sweetser: there has indeed been a change, but - at least until recently - more in the scope than in the method of semantic research.

\section{1. "False dichotomies"?}

Langacker (1987, p. 18) states: "[G]rammar vs. lexicon, morphology vs. syntax, semantics vs. pragmatics ... I regard all of these as false dichotomies" Why is this the case? Because each of these pairs, instead of being a division into two mutually exclusive groups, constitutes a "continuum" where "two extremes" are connected by a succession of "intermediate cases" (ibidem). Is it then correct to say that there is a gradual (rather than dichotomous) distinction between (e.g.) grammar and lexicon? Surprisingly, this too is deemed incorrect: "There is no meaningful distinction between grammar and lexicon" (p. 3; emphasis added), not even a gradual one. Just to make the point crystal clear, it is reasserted later: "I do not believe that either the distinction between grammar and lexicon or that between semantics and pragmatics can ultimately be maintained" (p. 449; emphasis added; also 1991a, pp. 514-516). This is very difficult to understand. Let us ask once again: Why is there no distinction between lexicon and grammar? And this is the answer that is offered: "Lexicon and grammar form a continuum" (Langacker, 2007, pp. 427; also p. 438).

Clearly some clarification is called for. Let us start with a simple example: "the existence of pink does not undermine the distinction between red and white, and dawn doesn't indicate that day and night are really the same" (Paulos, 1990, p. 63). This should be selfevident but apparently it is not. Otherwise Pap's (1958, p. 401) following remark would be pointless: "But to deny a distinction just because of its vagueness is, of course, a semantic naiveté of the first order."

In this section I intend to show that cognitive semantics scholars often fall prey to the semantic naiveté which Pap is warning against. In the attempt to get rid of the (simplistic) black-and-white thinking, it unwittingly falls back upon it, performing the following type of (fallacious) inference: Dichotomous distinctions are genuine ones but they do not exist; gradual distinctions exist but they are not genuine, or "meaningful", ones; ergo: no ("meaningful") distinctions exist. A continuum from A to B is taken to entail that there is no difference, or at most a "meaningless" one, between A and B.

\subsection{Semantics vs. pragmatics}

It is often maintained that de Saussure invented the langue vs. parole distinction. This is a mistake, as Coseriu (1975 [1958], pp. 16-18) correctly notes. Without some such distinction, no grammar could ever have been written. Hegel, for instance, already distinguished "Rede 
und ihr System, Sprache" (= "speech and its system, language") (ibidem). For Whitney (1979 [1875], p. 280), each language is an "institution", and yet "various in the different individuals". Prior to de Saussure, analogous distinctions such as "(sozialer) Sprachusus vs. (individuelle) Sprechtätigkeit" and "Sprachzustand vs. Rede" were postulated by Paul and von der Gabelentz, respectively. From among later distinctions, let us single out "Sprachgebilde vs. Sprechakt" (Trubetzkoy), "system vs. process" (Hjelmslev), and "code vs. message" (Jakobson).

If no grammar can be written without one or another version of the langue vs. parole distinction, the same must be true of Cognitive Grammar as well; and indeed it is (or so it seems): the counterpart of this dichotomy is "linguistic convention vs. usage event" (cf. Langacker, 1987, pp. 76-78). I use the word dichotomy on purpose, because in Figure 2.5 (p. 77) "the boundary between convention and usage" is clearly indicated by a vertical line. Here we really have to do with a false dichotomy. Why? Because new forms and meanings constantly emerge from parole/usage by means of gradual conventionalization. Later the distinction is reformulated as the one between "linguistic system" and "usage event" (2007, pp. 428-429).

In the study of meaning, the semantics vs. pragmatics distinction coincides with langue vs. parole. In a more refined scenario, it is possible to postulate a third level between these two extremes, namely an "intermediate layer formed of conventions or habits of use" (Levinson, 2000, p. 23). This would be the logical thing to do. Instead, as we have seen, Langacker (1987, p. 449) abandons the semantics vs. pragmatics distinction altogether. The result is what Levinson (2000, p. 243) vividly characterizes as "a horrid cocktail of semantics and pragmatics".

There is an interesting sequel to the situation described in the two preceding paragraphs. In response to the criticism by Levinson and others, Langacker (2007) performs an about-face, formulated as a clarification of his earlier position: "[Cognitive Grammar] does not deny ... the possibility of distinguishing [pragmatics] from semantics. It merely posits a gradation such that notions which are indisputably semantic or pragmatic lie toward opposite extremes of a scale" (p. 432). But this is not just a clarification, this is a fundamental revision. Denying any distinction at all between A and B (as Langacker did before) is not the same thing as saying that this distinction is a gradual one (as he now does). By implying that these two options are identical, he in fact perpetuates the earlier mistake.

In the traditional context, the semantics vs. pragmatics distinction is straightforward: "In semantics, the sentence I will come to see you at midnight has just the meaning of an assertion. (Which assertion? - this is evident from the lexical content and the grammatical structure.) In pragmatics, the same sentence (once uttered) becomes - depending on the context - either a promise (= Romeo is speaking to Juliette) or a threat (= a vampire is speaking to his future victim)" (Itkonen, 2008a, p. 284). Let us now take it for granted that this (gradual) distinction has been fully endorsed by Cognitive Grammar. What follows?

Let us recall the equations "meaning = conceptualization $=$ occurrence of cognitive events" (Section 4). Cognitive events ("defined as neurological occurrences") occur very rapidly and for the most part subconsciously. How should they qua meanings be split into semantic and pragmatic ones? There is no coherent answer. Of course, it is possible to distinguish between event-tokens and event-types (Section 6), but this is beside the point. Just as well any physical regularity could be said to have its semantics and pragmatics.

The term usage needs additional clarification in the present context. In the Wittgensteinian tradition, use equals convention (= norm, rule). But in the present distinction between convention and usage, the latter term stands for the Saussurean parole, i.e. behaviour either conforming to or deviating from the convention (= langue). 


\subsection{Lexicon vs. grammar}

"Lexicon and grammar form a continuum" (Langacker, 2007, p. 427; also p. 423, 438). This statement can mean at least three different things. First, there is the part vs. whole distinction: word vs. sentence, or morphology vs. syntax. Second, when the distinction between word and sentence is attenuated, as in typical polysynthetic constructions, the attention shifts to possible seams in the grammatical structure: derivation vs. inflection. Third, there are strong asymmetries (if not downright dichotomies) between lexical vs. grammatical morphemes.

"[M]orphology vs. syntax [is one of the] false dichotomies" (1987, p. 12). "There is otherwise no sharp distinction between [morphology and syntax]" (2007, p. 441). By now, we are fully prepared to encounter only gradual distinctions. But where absolute (= dichotomous) distinctions do exist, they must be recognized for what they are. Consider the situation where a chair is located behind a table. There is an ontological gap that separates the two things from the behind-relationship that holds between them: "A relationship ... presupposes the conception of the entities related" (Langacker, 1997, p. 263). There is also a gap between red and white, but they both are colors, which means that the gap, instead of being an ontological one, can be gradually filled. By contrast, no analogous bridge can be gradually built between thing and relationship: a relationship cannot be transformed into something more and more material until it reaches the stage of concrete thinghood. The same is true of the distinction between word order $(=\operatorname{syntax})$ and word $(=$ morphology). There is no way that the order of the words in (30-31) can become an additional word. This means that there is no false dichotomy between word order and word.

(30) Men love women.

(31) Women love men.

Next, we must consider the situation where the word vs. sentence distinction disappears, as is often the case in polysynthetic constructions. Does the lexicon vs. grammar distinction disappear as well? Interestingly, while the distinction now becomes gradual, it still constitutes the necessary background for adequate description. Consider the following West Greenlandic example.

(32) niqi-tur-vuq

meat-eat-3p.sg

$\mathrm{S} / \mathrm{he}$ ate meat

(33) $\quad$ [niqi-[tur-vuq] $]=\quad$ [lexical-[grammatical] $]$

(34) $[$ niqi-[tur-[vuq]]] = [lexical-[derivational-[inflectional]]]

The sentence (32) must be analyzed in two steps. First, there is the basic distinction between lexical and grammatical, as in (33). Second, grammatical is divided into derivational and inflectional, as in (34). More precisely, -tur- is both an affixal verb and a derivational affix, i.e. an affix which, applying to the noun niqi, produces the denominal verb niqi-tur-. Denominal verbs require the intransitive (rather than transitive) inflection, exemplified here by the $3 p . s g$ form -vuq.

The macroword of West Greenlandic constitutes a tight package where the lexical element is on the left, the inflectional element is on the right, and everything in between qualifies as derivational, in such a way that meanings become less lexical and more grammatical in the left-to-right direction. (33-34) summarize this very transparent structure. Let us consider the more complex example (cf. Fortescue, 1984, p. 315; also Itkonen, 2005b, pp. 210-213) in (35). 
(35) tusaanngitsuusaartuaannarsinnaanngivipputit [tusaar-nngit-suq]-usaar-tuaannar-sinnaa-nngit-vig-vutit [hear-NEG-ACT.PRT]-pretend-always-can-NEG-EMPH-2p.sg

"You simply cannot pretend not to be hearing all the time"

The sentence begins with a lexical unit, i.e. a nominal ('not-hearing') formed with (NEG plus) the active participle ending -suq, followed by the affixal/derivational verb -usaar('pretend'), and it closes with the inflectional unit -vutit (2p.sg); and the space in between is filled with temporal, modal, negative, and emphatic units.

Such traditional distinctions as compounding vs. derivation vs. inflection are abandoned by Cognitive Grammar. Why? The answer is, once again, that the boundaries involved are not "separate", "discrete" (Langacker, 2007, p 424), "precise", "definite", "specific" (p. 425), "particular" (p. 428), or "sharp" (p. 441). Here we have it again, the deepseated suspicion of gradual distinctions, masquerading as a critique of "sharp" distinctions. Recent volumes on compounding, derivation, and inflection in the Oxford Handbook series, for instance, testify to the imperative need for the corresponding distinctions. No analysis of (32-35) is possible without this tripartite classification. It can be abandoned only to be immediately adopted again.

To put it roughly, grammaticalization is a process where the input is lexical while the output is grammatical: as the form shrinks, the meaning expands. If the lexical vs. grammatical divide is abandoned, grammaticalization becomes incomprehensible, or a process with no beginning and no end.

"Suffix" and "prefix" designate units that express grammatical meanings, as opposed to (lexical) units that express lexical meanings. Tamil and Swahili exemplify, respectively, suffixing and prefixing languages. If the lexical vs. grammatical divide is abandoned, as suggested by Langacker (2007), there is no longer any typological difference between Tamil or Swahili, which is not a meaningful result.

In conclusion, the fundamental importance of the lexical vs grammatical distinction is asserted by two giants of linguistic theorizing: "Boas astutely disclosed the obligatoriness of grammatical categories which distinguishes them from lexical meanings ... Concepts which are grammaticalized and consequently obligatory in some languages [may be] lexicalized and merely optional in others" (Jakobson, 1990 [1959], p. 328; emphasis added).

\subsection{Semantic pole (= conceptualization) vs. phonological pole (= expression)}

In Cognitive Grammar, only two levels are needed for linguistic description, namely semantics and phonology. But, as implausible as it may sound, in his relentless fight against "false dichotomies", Langacker is ultimately willing to abandon even this last distinction.

As documented in Section 4, semantics is about conceptualization; conceptualization is identical with concept-formation; but concept-formation applies not only to meanings but also to forms, including the minimal formal units. Therefore Langacker (1987) infers that, the appearances notwithstanding, traditional phonology too is in fact subsumable under (an extended notion of) semantics: “... sounds are like other concepts" (p. 78); "Meanings are conceptual entities, so the conceptualization of a sound can also be considered a meaning" (p. 80). The conceptualization vs. expression distinction turns out to be just another false dichotomy: in language there are no (genuine) distinctions or differences at all.

But why should we stop here? Concept-formation applies to the entire universe; and once all false dichotomies have been deleted, there remains nothing that is not meaning. 
Within this huge totality, the properly linguistic meaning is seen to dwindle into insignificance.

\subsection{Analytic vs. synthetic}

Necessary truth, generally identified with analyticity, was shown to be an indispensable tool for semantic analysis in Subsections 8.1 and 10.2. The issue may be further clarified by means of (36-39).

(36) No unmarried man is married.

(37) No bachelor is married.

(38) No bachelor is unhappy.

The analyticity of (36) is accepted by everybody, including Quine (1961 [1953]), who calls (36) "logically true" (p. 22). (37) too is taken to be analytic by Pap (1958, p. 96), Quinton (1967, p. 123), and Hughes and Cresswell (1972, p. 23), but Quine (1961 [1953], pp. 23-32) disagrees. For the sake of argument, let us agree with Quine. Hence, (37) is less analytic than (36). (38) in turn is fully synthetic, or at least (much) more synthetic than (37). What follows? Have we shown that there is no analytic vs synthetic distinction? Of course not! We have shown that there is a gradual (rather than absolute) analytic vs synthetic distinction. Contrary to common misunderstandings, this result agrees with Quine's own intentions: "I am concerned to urge the empirical character of logic and mathematics no more than the unempirical character of theoretical physics [let alone of sentences like (38)]; it is rather their kinship that I am urging, and a doctrine of gradualism" (Quine, 1970, p. 100; emphasis added).

There is a fundamental difference between (37) and (38), irrespective of whether (37) is taken to satisfy each and every criterion of analyticity. It makes sense to test the truth of (38) by interviewing a sample of 1000 bachelors, but the person who treats (37) in the same way is rightly considered a moron. If such a person can be found, s/he is also likely to claim in the name of encyclopedic semantics that, in order to verify the truth of (39), no ("unscientific") intuition is needed, only ordinary hard-nosed observation: "When Bill ran from B to C, he was moving all the time, I saw it with my own eyes!"

(39) If A ran from B to C, then A moved from B to C.

On the other hand, the gap between (37) and (38) can be filled by adding an increasing number of intermediate cases which, taken together, constitute a continuum between (36) and (38). Thus, there is a wide consensus on the need for gradualism: "The distinction between necessary truth and empirical truth appears somewhat less than clear-cut” (Pap, 1958, p. 391). "It goes without saying that the notion of analyticity in natural language can only be a relative one... But relativity must not be confused with non-existence" (Itkonen, 1970b, p. 8). "Holism blurs the supposed contrast between the synthetic sentence, with its empirical content, and the analytic sentence, with its null content" (Quine, 1981, p. 71). Notice that the contrast is blurred, not eliminated. This is all that matters.

In conclusion, the following claim can be accepted, only if "tenable" has (rather arbitrarily) been redefined as "absolute": "Quine (1953) successfully argued that there is no tenable analytic-synthetic distinction" (Lewandowska-Tomaszczyk, 2007, p. 146). 


\section{What makes a theory "usage-based"?}

In Subsection 11.1 a distinction was made between convention and usage; and: "Cognitive grammar ... is a usage-based theory" (Langacker, 1987, p. 46). Let us evaluate this claim.

Chapter 1 of Langacker (1987), for instance, contains exactly 50 examples, all of which are based on Langacker's own linguistic intuition, i.e. none of which is based on any actual usage. For additional confirmation, let us single out Chapter 10 of Langacker (1991b), which bears the title "A Usage-Based Model". What is the usage this model is based upon? It consists of the sentences given in (40-49).

(40) Tom has an uncle, and Bill does too.

(41) Tom has two ears, and Bill does too.

(42) Tom is painting, and Bill is too.

(43) Tom is talking, and Bill is too.

(44) Tom is writing, and Bill is too.

(45) ?The fire is burning, and the bacon is too.

(46) Well, the fire is still burning. Oh my god! The bacon is too!

(47) He's a pig.

(48) You're a rat.

(49) That lawyer is a real fox.

Again, it is immediately evident that (40-49) are not based on any corpus of utterances that would exemplify actual usage. Rather, they are self-invented example sentences based on the grammarian's own linguistic intuition. Therefore they are identical with the standard data of generative grammar, for instance, with those 39 sentences that constitute the entire data base of Chomsky (1957) (cf. Itkonen, 2003b, Ch. 4). There is no reason why Chomsky, when inventing (50), could not have backed it up with some imaginary usage, just as Langacker is presumably doing with (40-49).

(50) The scene of the movie was in Chicago.

But imaginary usage is not usage, just as "the result of an imaginary experiment is [not] the result of an experiment" (Wittgenstein, 1958, §265). On the other hand, if "usage" is interpreted as normatively sanctioned use (convention), the use of examples like (40-49) and linguistic intuition in general would of course be fully valid.

How are conventions/norms investigated? By means of either correct sentences that accord with them or incorrect sentences that deviate from them: "speakers clearly have some conception of what does or does not accord with linguistic convention" (Langacker, 1987, p. 27). Consequently, as shown by (40-49), Cognitive Grammar turns out to be a conventionbased theory.

Of course, the idea of usage-based linguistic description is not just an empty fiction. It has been fully implemented in Labov-type variationist sociolinguistics and, more generally, in corpus linguistics. Actual usage is located in space and time, and the principal explanatory notion of spatio-temporal phenomena is that of causation: "Empirical linguistics is supposed to be concerned with regularities exhibited by actual linguistic behaviour of real (i.e. nonideal) speakers ... I state it as a desideratum of any adequate methodology of empirical linguistics that it should provide causal models for linguistic behaviour" (Itkonen, 1977, p. 29; original emphasis). The requisite notion of statistical-causal model is taken from Boudon (1974), and it is concretely illustrated as follows: "Consider the well-known case of the 
elimination of the word-final $-t /-d$ in some dialects of English (cf. Labov 1972: 222). We can identify the following variables: $\mathrm{x}-\mathrm{a}$ (dependent variable $)=-t /-d$ disappears $(=\mathrm{A})$ or not $(=$ $\sim \mathrm{A}) ; \mathrm{x}-\mathrm{b}=$ the following word begins with a consonant $(=\mathrm{B})$ or not $(=\sim \mathrm{B}) ; \mathrm{x}-\mathrm{c}=$ a morpheme boundary does not precede $(=\mathrm{C})$ or does precede $(=\sim \mathrm{C})$; $\mathrm{x}-\mathrm{d}=$ lower working class $(=\mathrm{D})$, upper middle class ( D)" (Itkonen, 1977, p. 31).

Labov (1972) is content to note how $\mathrm{x}$-a is influenced by the independent variables $\mathrm{x}-\mathrm{b}$, $\mathrm{x}-\mathrm{c}$, and $\mathrm{x}-\mathrm{d}$. Itkonen $(1977$, p. 32) offers a more differentiating model with two additional statistical causes, namely an interaction between $x-b$ and $x-c$ as well as a second-level interaction between this interaction and $x-d$. This analysis also exemplifies Salmon's (1971) notion of statistical explanation which consists in increasing the probability of the dependent variable by increasing the number of the independent variables. ${ }^{10}$

The confusions discussed in this subsection result from assigning an inordinately wide interpretation to traditional intuition/convention-based analysis: on the one hand, it is mistaken for ("neurological") analysis of the unconscious mind (Section 6); on the other, it is mistaken for observational-statistical analysis of actual behaviour.

\section{Generalization and analogy}

Analogy is defined as structural similarity (cf. Itkonen 2005a). A, B, C, etc. are structurally similar or analogous if (and only if) they share a common structure X. Here A, B, and C may stand either for particular units or for entire knowledge-domains or for anything in between. Extracting $\mathrm{X}$ from $\mathrm{A}, \mathrm{B}$, and $\mathrm{C}$ is tantamount to making a generalization over $\mathrm{A}, \mathrm{B}$, and $\mathrm{C}$. There are no non-analogical generalizations. (Those concerning phenomena with no internal structure - e.g. patches of colour - may look like a counter-example, but in this case it is the context which provides the requisite structure.) Analogies may be right or wrong, easy or difficult to grasp. Depending on the ontology at hand, analogies are either discovered or invented. The analogy between water waves, sound waves, and light waves was discovered during centuries of research. Von Wright (1968, pp. 13-14) asserts to have invented the general idea of modern deontic logic (the logic of obligations, permissions, and prohibitions) on the analogy with modal logic (the logic of necessity, possibility, and impossibility). Similarly, Chomsky invented generative grammar on the analogy with axiomatic logic. Each and every culture invents its own version of the analogy between microcosmos and macrocosmos.

Tuggy (2007, p. 83) states that "Langacker equates the ability to generalize with the extraction of schemas"; and further on: "Just about anything ... will be handled within Cognitive Grammar by positing a schema (or schemas). This will include syntactic rules, phonological rules, diachronic rules, semantic rules, ... morphological rules ..." (p. 94). Logically enough, I make the same claims for analogy (Itkonen 2005a). In doing so, I am just elaborating on Householder (1969, p. 889): "In the ordinary use of the term, analogizing is precisely and only what a linguist does in writing a grammar which purports to be a model of the speaker's competence". This was said in response to the following claim: "Our ability to create and understand novel sentences cannot be accounted for by any appeal to the human capacity of analogizing" (Langacker, 1968, p. 21).

Still, the virtues of analogy are too obvious to be permanently denied: "If the notion of analogy is made explicit, and if rules are conceived as schemas, there is no substantial difference between analogical and rule-based descriptions" (Langacker, 1987, p. 447). This is in agreement not just with Fred Householder but with Raimo Anttila as well: "Any system of

\footnotetext{
${ }^{10}$ For futher discussion, see Itkonen (1980, pp. 349-364), (1983, Ch. 6), (2003a, Ch. VI), (2013-2014, Sect. 7), Itkonen \& Pajunen (2010, pp. 114-148).
} 
grammatical description can be reduced to analogical terms based on the kind of relations used in each such system" (1989 [1972], p. 88).

Yet others seem anxious to limit the scope of analogy. According to Tuggy (2007: 111), "analogy is most clearly to be invoked where there is no pre-established schema to directly sanction the newly coined structure". The incoherence of this statement cries out to be corrected. Why should X be called (nothing but) "analogy" as long as it is not fully entrenched, but "schema" as soon as it has become entrenched? During this entire process, $\mathrm{X}$ has remained the same, i.e. an analogy, and only its degree of entrenchment has changed. To designate only the first stage of this process as analogy is a ploy intended to marginalize this term and to leave the pride of place to schema.

In this instance, terminological diversity conceals de facto agreement. The term schema has been used in many different meanings (cf. Sinha 2007). Analogy, by contrast, has acquired a well-established meaning both in linguistics and in the neighbouring disciplines. The rational thing to do is to replace the former by the latter.

\section{Functional explanations}

Cognitive Grammar involves three increasingly ambitious levels: (i) descriptive framework (primarily applied to European languages), (ii) cross-linguistic structures and their common core, (iii) "functional explanations for the findings at levels one and two" (Langacker 2007, p. 423). The movement from level one to level two represents the inductive stage while level three presumably stands for the highest stage.

According to Langacker's own assessment, Cognitive Grammar has so far concentrated on consolidating the work on the first level. It is natural that the work on the second level has been done within the general framework of typological research. This is why such functional explanations as have been proposed up to now apply in the first place to cross-linguistic data.

What is it, exactly, that "functional explanation" stands for? At least the following meanings have to be distinguished: (a) rational explanation $=$ an action or activity is explained as being the means which the agent (unconsciously) believes to be needed to achieve the goal that s/he (unconsciously) entertains; (b) functional explanation $=$ the existence of an organ is explained by the effects of its own activity (e.g. the effect/function of the heart is to maintain blood circulation); (c) evolutionary explanation $=$ (persistence traits of) mutations are explained insofar as they turn out to be beneficial (= "functional") for the survival of the species.

Having reviewed these alternatives, Itkonen (2013b) adduces several examples to show that only point (a) genuinely applies to linguistics. A more comprehensive overview is offered by Itkonen (2013-2014), where no less than eight different types of explanation are scrutinized as for their relevance to linguistics.

It is interesting to note that cognitive semantics has paid relatively little attention to the purposive or goal-directed nature of human behaviour. Although it is fashionable to emphasize the "dynamic" character of one's own framework, such terms as goal, intention, or rationality are not to be found in the index of Geeraerts and Cuyckens (2007). And yet, it is natural to ask: What is the force that makes people use language, in the first place? In general, this question is left unanswered. Those looking for an answer might want to consult Itkonen (1977, 1980, 1981b, 1983), where a rational/causal conception of language and linguistics, as explicated by the corresponding type of explanation, has been expounded in extenso.

To put it simply, the driving force turns out to be unconscious rationality. The majority of linguists seem somewhat reluctant to accept this notion (assuming that they are familiar with it). It has found acceptance outside of linguistics. To give an extreme example, Harford (2008) shows in great detail that in their own environment e.g. gambling, drug addiction, and 
prostitution exemplify rational behaviour. So why not language use and change? Besides, rationality is not restricted to human beings. The work by Dickinson (1988) and others demonstrates that " $[\mathrm{r}]$ ational explanation applies ... also to animal behaviour, e.g. the behaviour of rats" (Itkonen, 2003b, p. 61). Harford (2008) agrees: "Given the chance, even rats can be rational" (p. 20). The sceptical minds can perhaps be swayed by the following argumentum ad auctoritatem: "Darwin viewed metaphysical objections to extending human mental qualities to animals as 'arrogance' ... [I]t was no more absurd to speak of a higher mammal showing fear, reasoning power or pleasure than to call the structure on the end of a chimpanzee's forelimb a hand" (Howard 1982, pp. 66-67).

\section{Conclusions}

The goal of this article has been to examine not cognitive linguistics is general, or even cognitive semantics, but one common, though not universally shared idea within this linguistic school: an individual-psychological (= mentalist) conception of linguistic meaning. For the most part, the discussion has been critical, showing that at least in some of their writings authors such as Ronald Langacker, George Lakoff, Mark Johnson, Len Talmy, David Tuggy, Eve Sweetser, Dirk Geeraerts and others have failed to respect one or more of the following (partly overlapping) distinctions: social vs. individual, conscious vs. unconscious, norm/convention vs. behaviour, conceptual vs. causal, analytic/necessary vs. synthetic/contingent, intuition vs. introspection vs. sense-perception.

The spirit of the analysis has, however, been "therapeutic" rather than purely negative. For example, it was shown that a "meaning is use", or conventionality-based approach to meaning is in fact well-represented in the field, above all in the model of Cognitive Grammar, even if this is not always acknowledged. While not based on actual usage, by abandoning the notion of "imagery" for the more intersubjective concept of construal (Möttönen, 2016), by emphasizing conventionality and eventually acknowledging the division between (conventional) semantics and (contextual) pragmatics, as well as the role of analogy, the model has at least approached the social notion of meaning endorsed in this article.

In sum, it seems to be indeed as Harder (2010) argues that Cognitive Linguistics is experiencing a "social turn". Younger scholars like Brandt (2013), Blomberg (2015) and Möttönen (2016) have made further steps to resolve some of the problems of cognitive semantics by integrating sociality through notions like intersubjectivity, "enunciation", and the "sedimentation of meaning". That, however, is the topic of another story.

\section{Acknowledgments}

Over the years, my thinking on Cognitive Linguistics in general, and on Cognitive Grammar in particular, has been shaped by discussions with Anneli Pajunen, Chis Sinha, and Jordan Zlatev. The original, unpublished Finnish-language version of this article benefitted from comments by Ilona Herlin and Laura Visapää. I owe a special debt of gratitude to Michael Kac for his copious comments on the first English-language version of this article. The final version was made much more readable thanks to two anonymous referees. Once again, Jordan Zlatev made a fine job of editing the text, streamlining the argument and displaying his gift of detecting, as it were, the constructive element also in what was originally intended to be destructive. Posthumous thanks go to Erik Stenius (d. 1990), who, having been a major influence on Itkonen (1970a), consented to serve as the second supervisor of my 1974 dissertation. 


\section{References}

Anttila, R. (1989 [1972]). Historical and comparative linguistics. Amsterdam: Benjamins. Bechtel, W., \& Abrahamsen, A. (1992). Connectionism and the mind. Oxford: Blackwell. Behme, C. (2014). Review article: A ‘Galilean' science of language. Journal of Linguistics, 60, 671-704.

Bischoff, S., \& Jany, C. (Eds.) (2013). Functional approaches to language. Berlin: Mouton de Gruyter.

Blomberg, J. (2015). The expression of non-actual motion in Swedish, French and Thai. Cognitive Linguistics, 26(4), 657-694.

Bloomfield, L. (1933). Language. New York: Holt, Rinehart \& Winston.

Bohnemeyer, J., \& Pedersen, E. (Eds.) (2011). Event representation. Cambridge: Cambridge University Press.

Boudon, R. (1974). The logic of sociological explanation. Harmondsworth: Penguin Books.

Brandt, L. (2013). The communicative mind. Newcastle: Cambridge Scholars.

Brown, R. (1958). Words and things. New York: Free Press.

Carr, P. (1990). Linguistic realities: An autonomist metatheory for the generative enterprise. Cambridge: Cambridge University Press.

Chafe, W. (1994). Discourse, consciousness and time: The flow and displacement of conscious experience in speaking and writing. Chicago: The Chicago University Press.

Chafe, W. (2013). Toward a thought-based linguistics. In S. Bischoff, \& C. Jany (Eds.) pp. 107-130.

Chomsky, N. (1957). Syntactic structures. The Hague: Mouton.

Chomsky, N. (1965). Aspects of a theory of syntax. Cambridge, Mass.: The MIT Press.

Chomsky, N. (1986). Knowledge of language: Its nature, origin and use. New York: Praeger.

Clark, H. (1996). Using language. Cambridge: Cambridge University Press.

Cohen, L.J. (1986). The dialogue of reason: An analysis of analytical philosophy. Oxford: Clarendon Press.

Coseriu, E. (1974 [1958]). Synchronie, Diachronie und Geschichte. München: Wilhelm Fink Verlag.

Croft, W. (2000). Explaining language change: An evolutionary approach. London: Longman.

Dahl, Ö. (2004). The growth and maintenance of linguistic complexity. Amsterdam: Benjamins.

Dickinson, A. (1988). Intentionality in animal conditioning. In L. Weiskrantz (Ed.), Thought without language (pp. 305-325). Oxford: Clarendon Press.

Edgley, R. (1970). Innate ideas. In Knowledge and necessity. Royal Institute of Philosophy Lectures, Vol. III (pp. 1-33). London: Macmillan.

Everett, D., \& Kern, B. (1997). Wari'. London: Routledge.

Fillmore, C.J. (1971). Verbs of judging: An exercise in semantic description. In C.J. Fillmore \& D.T. Langendoen (Eds.), Studies in linguistic semantics (pp. 273-296). New York: Holt, Rinehart \& Winston.

Fortescue, M. (1984). West Greenlandic. London: Croom Helm.

Frege, G. (1949 [1892]). On sense and nominatum. In H. Feigl \& W. Sellars (Eds.), Readings in philosophical analysis (pp. 85-102). New York: Appleton-Century-Crofts, New York.

Geeraerts, D. (2010). Theories of lexical semantics. Oxford: Oxford University Press.

Geeraerts, D. \& H. Cuyckens (Eds.) (2007). The Oxford handbook of cognitive linguistics. Oxford: Oxford University Press. 
Givón, T. (1991). Serial verbs and the mental reality of 'event': Grammatical vs. cognitive packaging. In E. Traugott \& B. Heine (Eds.), Approaches to grammaticalization, vol. I (pp. 181-227). Amsterdam: Benjamins.

Gonzales-Marquez, M., Mittelberg, I., Coulson, S., \& Spivey, M.J. (Eds.) (2007). Methods in cognitive linguistics. Amsterdam: Benjamins.

Haiman, J. (1980). Hua: A Papuan language of the Eastern Highlands of New Guinea. Amsterdam: Benjamins.

Haiman, J. (1985). Natural syntax: Iconicity and erosion. Cambridge: Cambridge University Press.

Harder, P. (1999). Partial autonomy: Ontology and methodology in cognitive linguistics. In T. Janssen \& G. Redeker (Eds.), Cognitive linguistics: Foundations, scope and methodology (pp. 195-222). Berlin: Mouton de Gruyter.

Harder, P. (2010). Meaning in mind and society: A functional contribution to the social turn in cognitive linguistics. Berlin: DeGruyter Mouton.

Harford, T. (2008). The logic of life. London: Little, Brown.

Haukioja, T. (Ed.) (2006). Papers on language theory. University of Turku, Publications in General Linguistics, 10.

Hintikka, J. (1969). Models for modalities. Dordrecht-Holland: Reidel.

Householder, F. (1969). Review of Langacker (1968). Language 45(4), 886-897.

Howard, J. (1982). Darwin. Oxford: Oxford University Press.

Hughes, G.E., \& Cresswell M.J. (1972). Introduction to modal logic. London: Methuen.

Itkonen, E. (1969a). Semantiikan ja syntaksin suhteesta ['On the relationship between semantics and syntax', in Finnish]. Virittäjä 73, 217-237.

Itkonen, E. (1969b). Semantics as an analysis of language-independent reality. Mimeographed. Massachusetts Institute of Technology, $47 \mathrm{pp}$.

Itkonen, E. (1970a). An epistemological approach to linguistic semantics. Ajatus:The Yearbook of the Philosophical Society of Finland, 32, 96-142.

Itkonen, E. (1970b). Zwei verschiedene Versionen der Bedeutungskomponente. Linguistics, 59, 5-13.

Itkonen, E. (1974). Linguistics and metascience. Societas Philosophica et Phaenomenologica Finlandiae.

Itkonen, E. (1977). Causal Models in Linguistics. Publications of the Linguistic Association of Finland, 1, 25-35.

Itkonen, E. (1978). Grammatical theory and metascience: A critical investigation into the philosophical and methodological foundations of 'autonomous' linguistics. Amsterdam: Benjamins,.

Itkonen, E. (1980). Qualitative vs. quantitative analysis in linguistics. In T.A. Perry (Ed.), pp. 334-366.

Itkonen, E. (1981a). The concept of linguistic intuition. In F. Coulmas (Ed.), A Festschrift for native speaker (pp. 127-141). Mouton: The Hague.

Itkonen, E. (1981b). Rationality as an explanatory principle in linguistics. In H. Weydt (Ed.), Logos semantikos, vol. II (pp. 77-87). Berlin: Walter de Gruyter.

Itkonen, E. (1983). Causality in linguistic theory: A critical investigation into the philosophical and methodological foundations of 'non-autonomous' linguistics. London: Croom Helm.

Itkonen, E. (1991). Universal history of linguistics: India, China, Arabia, Europe. Amsterdam: Benjamins.

Itkonen, E. (1996). Concerning the generative paradigm. Journal of Pragmatics, 25, 471501. 
Itkonen, E. (1997). The social ontology of linguistic meaning. SKY: The Yearbook of the Linguistic Association of Finland, 10, 49-81.

Itkonen, E. (2002). Grammaticalization as an analogue of the hypothetico-deductive method. In I. Wischer \& G. Diewald (Eds.), New reflections on grammaticalization (pp. 413-422). Amsterdam: Benjamins.

Itkonen, E. (2003a). Methods of formalization beside and inside both autonomous and nonautonomous linguistics. University of Turku, Publications in General Linguistics, 6.

Itkonen, E. (2003b). What is language? A study in the philosophy of linguistics. University of Turku, Publications in General Linguistics, 8.

Itkonen, E. (2005a). Analogy as structure and process: Approaches in linguistics, cognitive psychology, and philosophy of science. Amsterdam: Benjamins.

Itkonen, E. (2005b). Ten non-European languages: An aid to the typologist. University of Turku, Publications in General Linguistics, 9.

Itkonen, E. (2008a). The central role of normativity in language and linguistics. In J. Zlatev et al. (Eds.), pp. 279-305.

Itkonen, E. (2008b). Concerning the role of consciousness in linguistics. Journal of Consciousness Studies, 15.6, 15-33.

Itkonen, E. (2011a). Papers on typological linguistics. University of Turku, Publications in General Linguistics, 15.

Itkonen, E. (2011b). On the role of induction in linguistic typology. In E. Itkonen, E. (2011a), pp. 177-190.

Itkonen, E. (2011c). On Coseriu's legacy. Energeia, III, 1-29. [Reprinted in E. Itkonen (2011a), pp. 191-227]

Itkonen, E. (2013a). Philosophy of Linguistics. In K. Allan (Ed.), The Oxford handbook of the history of linguistics (pp. 747-774). Oxford: Oxford University Press.

Itkonen, E. (2013b). Functional Explanation and its Uses. In S. Bischoff \& C. Jany, C. (Eds,), pp. 31-69.

Itkonen, E. (2013-2014). On Explanation in linguistics. Energeia, V, 10-40.

Itkonen, E., \& Pajunen, A. (2010). Empiirisen kielitieteen metodologia [ 'The Methodology of Empirical Linguistics", in Finnish]. Helsinki: Suomalaisen kirjallisuuden seura.

Jackendoff, R. (1992). Languages of the mind. Cambridge Mass.: The MIT Press.

Jackendoff, R (2002). Foundations of language. Oxford: Oxford University Press.

Jakobson, R. (1990 [1959]). Boas' View of Grammatical Meaning. In L.R. Waugh \& M. Monville-Burston (Eds.), On Language (pp. 324-331). Cambridge, Mass.: Harvard University Press.

Johansson, S. (2011). Biolinguistics or Physicolinguistics? Is the Third Factor Helpful or Harmful in Explaining Language? Biolinguistics, 5.1-2

Johnson, M. (1987). The body in the mind: The bodily basis of meaning, imagination, and reason. Chicago: The University of Chicago Press.

Kac, M. (1974). Autonomous linguistics and psycholinguistics. Minnesota Working Papers in Linguistics and Philosophy of Language, 2, 43-47 [Reprinted in T. Haukioja (Ed.), pp. 129-133]

Kac, M. (1980). In defence of autonomous linguistics. Lingua, 50, 243-245.

Kahneman, D. (2011). Thinking, fast and slow. London: Allen Lane.

Katz, J.J. (1972). Semantic theory. New York: Harper \& Row.

Katz, J.J. (1981). Language and other abstract objects. Oxford: Blackwell.

Katz, J.J. (1985). Introduction. In J.J. Katz (Ed.), The philosophy of linguistics (pp. 1-16). Oxford: Oxford University Press. 
E. Itkonen

Kennedy, J.M. (1993). Drawing by the blind: Pictures to touch. New Haven: Yale University Press.

Kenny, A. (1975). Wittgenstein. London: Penguin Books.

Kenny, A. 1980. Aquinas. Oxford: Oxford University Press.

Koestler, A. (1967). The goast in the machine. London: Hutchinson.

Kroy, M. (1976). Mentalism and modal logic.Wiesbaden: Athenaion.

Labov, W. (1972). Sociolinguistic Patterns. Philadelphia: University of Pennsylvania Press.

Lakoff, G. (1987). Women, fire, and dangerous things: What categories reveal about the mind. Chicago: The University of Chicago Press

Lakoff, G \& Johnson, M. (1980). Metaphors we live by. Chicago: The University of Chicago Press.

Langacker, R.W. (1968). Language and its structure: Some fundamental concepts. New York: Harcourt, Brace \& World.

Langacker, R.W (1987). Foundations of cognitive grammar I: Theoretical prerequisites. Stanford: Stanford University Press.

Langacker, R.W (1991a). Foundations of cognitive grammar II: Descriptive applications. Stanford: Stanford University Press.

Langacker, R.W (1991b). Concept, image, and symbol: The cognitive basis of grammar. Berlin: Mouton de Gruyter.

Langacker, R.W (1997). A dynamic account of grammatical function. In J. Bybee, J. Haiman $\&$ S.A. Thompson (Eds.), Essays on language function and language type, dedicated to $T$. Givón (pp. 249-273). Amsterdam: Benjamins.

Langacker, R.W (2007). Cognitive grammar. In D. Geeraerts \& H. Cuyckens (Eds.), pp. 421462.

Lehrer, K. (1974). Knowledge. Oxford: Clarendon Press.

Levinson, S.C. (2000). Presumptive meanings: The theory of generalized conversational implicature. Cambridge, Mass.: The MIT Press.

Levinson, S.C. (2006). Cognition at the heart of human interaction. Discourse Studies, 8, 8593.

Lewandowska-Tomaszcyzk, B. (2007). Polysemy, prototypes, and radial categories. In D. Geeraerts \& H. Cuyckens (Eds.), pp. 139-169.

Lewis, D. (1969). Convention. Cambridge, Mass.: Harvard University Press.

López, S.A. (2009). Eugenio Coseriu y Esa Itkonen: Lecciones de la filosofía de la lingüística. Energeia, I, 1-49.

Möttönen, T. (2016). Construal in expression: An intersubjective approach to cognitive grammar. University of Helsinki.

Menn, L., Jill, C., \& Narasimhan, B. (2013). Towards an experimental functional linguistics: Production. In S. Bishoff \& C. Jany, C. (Eds.), pp. 207-245.

Mortelmans, T. (2007). Modality in cognitive linguistics. In D. Geeraerts \& H. Cuyckens (Eds.), pp. 869-889.

Mundle, G.W.K. (1970). Philosophical behaviourism. In Knowledge and Necessity. Royal Institute of Philosophy Lectures, vol. III (pp. 119-131). London: Macmillan.

Needham, R. (1972). Belief, language, and experience. Oxford: Blackwell.

Neisser, U. (1976). Cognition and reality. San Fransisco: Freeman.

Nuyts, J. (2001). Epistemic modality, language, and conceptualization. Amsterdam: Benjamins.

Pap, A. (1958). Semantics and necessary truth: An inquiry into the foundations of analytic philosophy. New Haven: Yale University Press.

Paul, H. (1975 [1880]). Prinzipien der Sprachgeschichte. Tübingen: Niemeyer. 
Pawley, A. (2011). Event representation in serial verb constructions. In J. Bohnemeyer \& E. Pedersen (Eds.), pp. 13-42.

Perry, T.A. (Ed.) (1980). Evidence and argumentation in linguistics. Berlin: De Gruyter.

Pickering, M.J., \& Branigan, H.P. (1999). Syntactic priming in language production. Trends in Cognitive Sciences 3(4), 136-141.

Popper, K. 1972. Objective knowledge. Oxford: Oxford University Press.

Poulos, J.A. (1990). Innumeracy: Mathematical illiteracy and its consequences. Harmondsworth: Penguin Books.

Putnam, H. (1978). Meaning and the moral sciences. London: Routledge.

Putnam, H. (1981). Reason, truth, and history. Cambridge: Cambridge University Press.

Quine, W.v.O. (1961 [1953]). From a logical point of view. Cambridge, Mass.: Harvard University Press.

Quine, W.v.O. (1970). Philosophy of logic. Englewood Cliffs, N.J.: Prentice-Hall.

Quine, W.v.O. (1981). Theories and things. Cambridge, Mass.: Harvard University Press.

Quinton, A. (1967). The a priori and the analytic. In P.F. Strawson (Ed.), Philosophical logic (pp. 107-128). Oxford: Oxford University Press.

Quinton, A. (1973). The nature of things. London: Routledge.

Ringen, J. (1975). Linguistic facts. In D. Cohen \& J. Wirth (Eds.): Testing linguistic hypotheses (pp. 1-41). Washington: Hemisphere Publishing Company. [Reprinted in T.A. Perry (Ed.), pp. 97-132]

Salmon, W. (1971). Statistical explanation and statistical relevance. Pittsburgh: University of Pittsburgh Press.

Sampson, G. (1980). Making sense. Oxford: Oxford University Press.

Sapir, E. (1921). Language. New York: Harcourt, Brace \& World.

Saussure, Ferdinand de. (1962 [1916]). Cours de linguistique générale. Paris: Payot.

Searle, J. R. (1969). Speech acts: An essay in the philosophy of language. Cambridge: Cambridge University Press.

Sinha, C. (2007). Cognitive linguistics, psychology, and cognitive science. In D. Geeraerts \& H. Cuyckens (Eds.), pp. 1266-1294.

Stenius, E. (1960). Wittgenstein's Tractatus: A critical exposition of its main lines of thought. Oxford: Blackwell.

Strawson, P.F. (1971 [1965]). Truth: A reconsideration of Austin's views. In Logicolinguistic papers (pp. 234-249). London: Methuen.

Susswein, N., \& Racine, T. (2008). Sharing mental states: Causal and definitional issues in intersubjectivity. In J. Zlatev et al. (Eds.), pp. 141-162.

Sweetser, E. (1990). From etymology to pragmatics: Metaphorical and cultural aspects of semantic structure. Cambridge: Cambridge University Press.

Sweetser, E. (1999). Compositionality and blending: Semantic composition in a cognitively realistic framework. In T. Janssen \& G. Redeker (Eds.), Cognitive linguistics: Foundations, scope, and methodology (pp. 129-162). Berlin: Mouton de Gruyter.

Talmy, L. (2000). Toward a cognitive semantics, vol. I: Concept structuring systems. Cambridge, Mass.: The MIT Press.

Tuggy, D. (2007). Schematicity. In D. Geeraerts \& H. Cuyckens (Eds.), pp. 82-116.

Vainio, S., Hyönä, J., \& Pajunen, A. (2003). Facilitatory and inhibitory effects of grammatical agreement: Evidence from readers' eye fixation patterns. Brain \& Language, 85, 197-201.

Vainio, S., Hyönä, J., \& Pajunen, A (2008). Processing modifier - head agreement in reading: Evidence for a delayed effect of agreement. Memory \& Cognition, 2, 329-340.

Von Wright, G.H. (1963a). Norm and action. London: Routledge.

Von Wright, G.H. (1963b). Varieties of goodness. London: Routledge. 
Von Wright, G.H. (1968). An essay in deontic logic and the general theory of action. Amsterdam: North-Holland Publishing Company.

Von Wright, G.H. (1998). Sielu, aivot ja käyttäytyminen ['Mind, Brain, and Behavior', in Finnish]. Ajatus: The Yearbook of the Philosophical Society of Finland, 55, 3-17.

Whitney, W.D. (1979 [1875]). The life and growth of language. New York: Dover.

Winch, P. (1958). The idea of a social science. London: Routledge.

Wittgenstein, L. (1958 [1953]). Philosophical investigations. Oxford: Blackwell.

Wittgenstein, L. (1969). On certainty. Oxford: Blackwell.

Zlatev, J. (2007). Spatial semantics. In D. Geeraerts \& H. Cuyckens (Eds.), pp. 318-350.

Zlatev, J. (2008a). The dialectics of consciousness and language. Journal of Consciousness Studies, 15.6, 5-14.

Zlatev, J. (2008b). The dependence of language on consciousness. Journal of Consciousness Studies, 15.6., 34-62.

Zlatev, J. (2008c). The co-evolution of intersubjectivity and bodily mimesis. In J. Zlatev et al. (Eds.), pp. 215-244.

Zlatev, J. (2010). Phenomenology and cognitive linguistics. In D. Schmicking \& S. Gallagher (Eds.), Handbook of phenomenology and cognitive science (pp. 415-446). Dordrecht: Springer.

Zlatev, J., Racine, T., Sinha, C., \& Itkonen, E. (Eds.) (2008). The shared mind: Perspectives on intersubjectivity. Amsterdam: Benjamins.

Author address

eitkonen@utu.fi

About the author

Esa Itkonen was born in 1944. He is professor Emeritus of General Linguistics (1982-2012) at the University of Turku, Finland; Dozent of Philosophy (1986-2012) at the University of Jyväskylä, Finland. Principal areas of interest: philosophy of linguistics, history of linguistics, linguistic typology 